\title{
Factors affecting Active Participation in B2B Online Communities: An Empirical Investigation
}

\begin{abstract}
There is a lack of understanding on the factors affecting active participation in Business-to-Business (B2B) Online Communities (OC). To address this gap, we developed a model based on two theories: Social Exchange Theory and the Information Systems Success Model. The model was validated by using survey data collected from 40 B2B discussion forums on LinkedIn $(n=521)$. Our work made a number of significant contributions including an integrated model of factors affecting active participation in B2B OCs and a new validated measure for active participation. Further, we proposed several guidelines which assist B2B OC providers in building and maintaining successful communitities.
\end{abstract}

Key words: B2B Online Communities, Active Participation, Social Exchange, and Information Systems Success

\section{Introduction}

Online Communities (OC) have been seen as a very popular research subject for the past two decades. This research specifically concerns with Business-to-Business relational OC (B2B OC). The UK Business Forum (ukbusinessforums.co.uk) and B2B discussion groups on LinkedIn are examples of B2B OC. Companies are increasingly investing and participating in OC. For example, past research has shown that approximately $70 \%$ of small businesses use some kind of OC [4]. B2B OC have revolutionized the way businesses communicate and interact, exchange information and knowledge, and build and maintain business relationships with one and other. Information and knowledge sharing can be seen as one of the main reasons for the existence of many OC including B2B OC $[1,3,5,6]$. Other specific benefits of OC for companies include accessing business intelligence and innovation opportunities [7-9], a means of expanding markets, accessing information at low cost [2, 10], and gaining competitive advantage [11]. However, a B2B OC cannot deliver these great benefits without active participation of its members [12-15].

Despite the importance of active participation for OC, there appears to be no reported research on what exactly active participation means and how it can be measured in the context of B2B OC. Although active participation in OC has attracted attention, there is still no agreement on what exactly active participation means and how it can be measured [16-18]. Moreover, past research provides very limited understanding of the factors affecting active participation in B2B OC. A considerable amount of research examined the participation phenomenon in various types of OC including online knowledge sharing communities [5, 7, 19-21], online travel communities [16, 22], social media $[4,13,23,24]$, online health communities [25, 26], online innovation communities [27, 28], B2B e-commerce [29], and C2C OC such as product review sites [30-37]. However, our analysis of the extant literature [25, 38-40] reveals that there is still a lack of research on what may affect active participation in B2B OC. Considering the growing importance of B2B OC for organisations, this study aims to close this research gap.

Drawing upon Social Exchange Theory (SET) and the Information Systems Success Model (ISSM), we developed and validated a research framework that provides a foundation for a better understanding of the factors affecting active participation in B2B OC. Our research makes significant contributions to OC research and practice. It helps to better understand the factors affecting members' active participation behaviour in B2B OC. Our study also provides some practical guidelines that can help community providers to develop and maintain successful communities. The remainder of this paper is organised as follows: we first discuss the theoretical background of our research, next we describe our research model, and then in sequence we present our developed hypotheses, research methodology, and empirical results. Finally, we summarise conclusions, contributions, implications, and the limitations of our study.

\section{Theoretical Background}

\subsection{Active Participation}

Active participation is the key success factor for OC [15]. For an online community to succeed and flourish there should be a large proportion of members who are actively involved in the community [20]. Despite the importance 
of active participation for OC, it is not clear what exactly active participation means and how it should be measured. For example, scholars have used the following approaches to measure the concept:

1. The number of postings - The majority of studies defined the active participants based on the number of postings $[18,41,42]$, but there were discrepancies in terms of what is the acceptable quantity of postings for an active participant. For example, some research suggests that active participants in OC are those members who post at least one message inside their community [18, 41], but other studies indicate that active participants are those members who post three or more messages or post above average $[17,18,43,44]$.

2. The number of postings and replies - Some researchers used both postings and replies as indicators for active participation [17]. For example, active participants were identified as those members whose posted messages , received at least one reply [45]. Based on this, it could be argued that OC members, who post several messages but do not get replies, are inactive participants.

3. Reading and posting - Other studies suggested that active participants can also be identified as those members who have been reading for some period of time and have just posted for the first time [46]. According to this, one could argue that members who post messages (e.g. asked questions), but hardly spent time reading messages could not be considered as active participants.

4. Average time spent in OC - Several studies suggested that the active participants of OC can be determined by the average time they spent in the community regardless of posting behaviour [16, 22]. This implies that OC members who lurk without making any content contribution are still considered as active participants.

Following our observation of the extant literature on participation in OC, this study argues that active participation measures, in particularly B2B OC, requires further attention for several reasons. Firstly, the current literature lacks a standard measure due to past studies suggesting that active participation in online community environments can be measured in different ways [16-18]. Secondly, the extant literature indicates that the definition and measure of the construct can vary from one online community type to another [17]. For example, in OC like discussion fora with the focus on information sharing, active participation can be determined through quantity of postings $[18,41]$. Whereas in OC like B2C OC with the focus of raising customer brand awareness, active participation can be determined by the time spent reading inside the community [47]. On the other hand, one could argue that in OC like social networking sites (e.g., Facebook) active participation can be measured by the number of different activities such as number of friends, shared files, shared videos, and likes. Thirdly, we found that the quantity of postings is extensively used to measure participation levels in various OC types. Yet the literature shows conflicting views on the number of posts that OC participants should make in order to be recognised as an active participant of the community $[18,41]$. Fourthly, we discovered that utilising the quantity of posts as an indicator for active participation has certain limitations. This is not just because of the contradictory findings in the literature, but also because online community members might provide high quantity but low quality posts and this is seen as a problem that can discourage other active participants [18]. Several researchers have also acknowledged this limitation and therefore called for a better measure for participation and further suggested that other factors (e.g., quality of posts) should also be included in the measure of active participation [48, 49]. For these reasons, we felt that it is necessary to conduct an exploratory study to define active participation and its measure in B2B OC. Based on the literature review and our exploratory study, we define active participation in $\mathrm{B} 2 \mathrm{~B} \mathrm{OC}$ as, 'community members carrying out several activities on a regular basis (e.g., daily or weekly). These activities include logging on to the community website, keeping their profile up to date, complying with community rules and regulations, posting quality messages that engender discussions, and replying to posted questions.' Accordingly, these are used as indicators of active participation in $\mathrm{B} 2 \mathrm{~B}$ OC in our research.

\subsection{SET and ISSM}

Our analysis of the extant online community literature suggests that the majority of past research [e.g., 20, 35, $40,42,49,51,52]$ focused on social, cognitive, motivational and contextual factors, and has paid little attention to technological factors [50]. However, OC have been recognised as socio-technical systems [53], and prior research has shown that technological factors have an effect on participation in online community environments [54]. Therefore, we combined SET and ISSM to develop our theoretical model. The combination of two theories not just helped us to propose a framework to explain the determinants of active participation in B2B OC, but also enabled us 
to gain a more comprehensive understanding of both social and technological related factors affecting active participation in B2B OC.

\subsubsection{SET and Active Participation}

SET is one of the most influential theories that has been successfully utilised to investigate the participation phenomenon in various community types as participation in $\mathrm{OC}$ has been recognised as social exchange $[5,20,42$, 55]. We selected SET for our research because it provides a suitable theoretical lens for us to understand the members' participation behaviour of B2B OC as compared to other theories such as Social Capital and Social Identity. Social Capital and Social Identity theories have been seen as effective in research that examined the participation phenomenon in OC like social networking sites, where the members are largely individuals who join such OC to gratify their individual needs (e.g., socialising). However, the members of B2B OC are business owners and managers, and therefore participation in this instance of OC is driven by the members' business needs rather than their personal needs. Participation in OC has been recognised as social exchange, which involves voluntary actions by individuals, groups and firms $[56,57]$. SET posits that all human relationships are formed by analyses of costbenefits and comparison of alternatives [58]. The theory views an online community as a place for exchanging resources (e.g., information and knowledge) between its participants (e.g., individuals, groups, or businesses). The theory suggests that participants of OC use a cost-benefit approach when interacting with each other [12]. From that perspective, in a B2B online community a member may decide to help other members (e.g., by replying to their posted messages) if he/she received help (e.g., received replied to his/her posted questions) in the past or expect to receive help in the future. For the contributor, the time spent replying to other people's messages can be seen as the cost and the received replies (i.e. advice received) can be seen as benefits. Thus, reciprocity is central to the theory [56]. Two types of reciprocity - 'direct reciprocity' and 'indirect reciprocity' are reported in the literature [12, 24, 49, $59,60]$. In OC, direct reciprocity is concerned with members who provide information and whom expect the recipients of that information to reciprocate with information in future. However, in the context of indirect reciprocity also known as "generalised" or "long term" reciprocity, the contributor would expect help from the community as a whole rather than from individual members who received information from them in the past. A close examination of the current literature suggests that reciprocity in B2B OC is mainly associated with generalised reciprocity as participation in $\mathrm{OC}$ is voluntary and members expect help from the whole community rather than individual members.

Along with reciprocity, commitment has also been seen as another vital aspect of SET, which has been a strong focus in the online community literature. Commitment arises from social exchanges [61] and has been described as one's intention to continue a relationship [56]. Thus, in the B2B online community context commitment focuses on the members' intention and desire to stay with the community. The paradigm has been seen as a complex and multidimensional construct $[56,61]$. Three dimensions of commitment (continuance commitment, affective commitment, and normative commitment) have been reported in the OC literature [61]. From a SET perspective, continuance commitment suggests that in $\mathrm{B} 2 \mathrm{~B}$ OC, members continue to participate in the community because they feel that leaving the community would prove costly and the received benefits from the community are not available elsewhere [61]. In contrast, normative commitment suggests that members may decide to stay with the community and to continue to participate in the activities because of a sense of obligation regardless of receiving any direct benefit from the community [61]. Differently, affective commitment suggests that members wish to stay and continue to participate in the community because of their strong sense of belonging and attachment to the community [61]. In our study, we only considered affective commitment as a predictor for active participation in B2B OC for several reasons. Firstly, the importance of affective commitment for B2B relationships is well documented in the literature. The construct has been seen as one of the key elements determining the outcomes of a B2B relationship, which ensures the relationship will continue in the future [62,63]. Secondly, normative commitment may not apply to the online community context because the construct focuses on feelings of obligation or responsibility and that does not make the participants make content contributions as participation is voluntary in OC [20,64]. Thirdly, we found very little evidence on how continuance commitment may influence active participation in OC. Past research findings indicate that continuance commitment is positively associated with lurking behaviour but not active participation behaviour [61].

Trust has been identified as another element of social exchange and therefore has been examined under SET [55, 57]. In OC settings, trust shapes and maintains the social exchange relationships, which can lead to active participation (e.g., knowledge sharing) afterwards [65]. In B2B OC, SET suggests that trust involves expectation of the members whose expectation is based on calculations which weight the costs and benefits of certain course of action to either trustor or trustee [57]. Accordingly, in B2B OC, if a member feels satisfied with the ability, integrity 
and benevolence of other members, he/she will participate actively to reciprocate the trustworthy relationship [65]. Similar to commitment, trust is also a complex and a multi-dimensional concept [66]. It has been defined differently throughout the literature. Gefen et al. [67] carried out a comprehensive literature review and found numerous different definitions of trust which illustrates the long lasting confusion about the concept. In our study, we refer to trust as the willingness of a party to be vulnerable to the actions of another party based on the anticipation that the other party will perform a certain action vital to the trustor, regardless of the ability to monitor or control the other party [21, 54, 68]. Our analysis of the literature revealed three types of trust: disposition to trust, institution based trust, and trusting beliefs [69]. After a thorough examination of these dimensions, we found only trusting beliefs to be important for active participation in B2B OC. For example, disposition to trust would not best capture the definition of trust in the context of online community, because it does not reflect on one's belief in others to be trustworthy [69, 70]. Institution based trust reflects an individual's perceptions of the institutional surrounding of a system and the structural assurance which makes the participants feel secure [71]. Accordingly, it could be argued that this type of trust is more applicable to $\mathrm{OC}$ like $\mathrm{B} 2 \mathrm{~B}$ e-commerce and $\mathrm{B} 2 \mathrm{C}$ e-commerce, than to $\mathrm{B} 2 \mathrm{~B}$ OC because transaction is the main purpose of the community in the former two types [72-74]. Trusting beliefs pertains to a type of trust that one agent has in another agent on an individual level [66]. Accordingly, we argue that this type of trust is more applicable to B2B OC, since the primary focus is the interaction between the community members (e.g., business owners and managers). This observation has been noted in prior research that examined the trust phenomenon in OC [75]. Further, three sub-constructs of trusting beliefs- ability ${ }^{1}$, benevolence ${ }^{2}$, and integrity ${ }^{3}$ are found in the literature $[69,76,77]$. Accordingly, we adopted these dimensions to capture the multi-dimensional aspect of the trust phenomenon in B2B OC.

\subsubsection{ISSM and Active Participation}

In addition to SET, we utilised ISSM to address the technology-related factors affecting members' active participation behaviour in B2B OC. Utilising the ISSM enabled us to investigate the technological related factors in B2B OC as compared to other theories (e.g., TAM) from a more comprehensive perspective. Particularly, in the IS literature TAM has been criticised for being too simplistic and parsimonious [78]. Moreover, selecting the model helped us to provide a better insight into the determinants of trusting beliefs in B2B OC. Past research suggests that when trust is examined in OC settings, the antecedents of trust also need to be examined [65]. Studies have shown that the antecedents of trust in OC can be classified into three categories: the community members, the community website, and the community provider [57, 65]. Three elements of the ISSM by DeLone and Maclean [79] such as system quality, information quality, and service quality, were found to be well-aligned to these three categories. Accordingly, they were selected as the antecedents of trusting beliefs as well as predictors for active participation in B2B OC. Other constructs (e.g., net benefits) seen as the dependent variable in the ISSM, were found to be irrelevant to our model and therefore were not included in our study. ISSM has been applied in various internet settings, including e-commerce, but very few studies have utilised the theory in the context of online community [80]. To the best of our knowledge, no study has empirically tested the impact of the three factors (information quality, system quality and service quality) on trust and on members' participation behaviour in B2B OC.

\subsection{Research Model and Hypotheses}

Based on the theoretical development outlined in the earlier section, we proposed the research model as shown in Figure 1. Three constructs (generalised reciprocity, trusting beliefs and affective commitment) from SET and three constructs (information quality, system quality, service quality) from ISSM are identified as the most relevant factors likely to affect members' active participation behaviour in B2B OC. The control variables in terms of community size and community age are also shown in the model.

\subsection{Generalised Reciprocity}

SET suggests that active participation in B2B OC depends on generalised reciprocity. Online community members tend to make more contributions if they think they will get pay-back for what they contribute [59]. Hence, in B2B OC, members will provide support and help to other members of the community by replying to their posted messages because they believe that they will benefit (e.g., they will receive replies to their posted questions) in the future. A large stream of research appears to emphasise the importance of generalised reciprocity in different types

\footnotetext{
${ }^{1}$ Ability based trust is concerned with an individual's belief that others are able to help fulfil his/her needs

${ }^{2}$ Benevolence based trust relates to an individual's belief that others voluntarily care about his/her needs

${ }^{3}$ Integrity based trust focuses on an individual's belief that others are telling the truth and will fulfil promises they make
} 
of OC. Lu and Yang [49] found that generalised reciprocity has a positive impact on the quantity of information posted in online discussion forums. Similarly, Ray et al. [20] indicated that generalised reciprocity encourages knowledge contribution intention in OC. Evidence of generalised reciprocity has also been noted in online transactional and online professional communities [35, 42]. Various empirical studies examined the impact of reciprocity on participation in various $\mathrm{OC}$ types. There is however limited evidence regarding reciprocity and its effects on participation in B2B OC. Accordingly this study hypothesizes that:

H1: Generalised reciprocity has a positive impact on members' active participation behaviour in B2B OC.

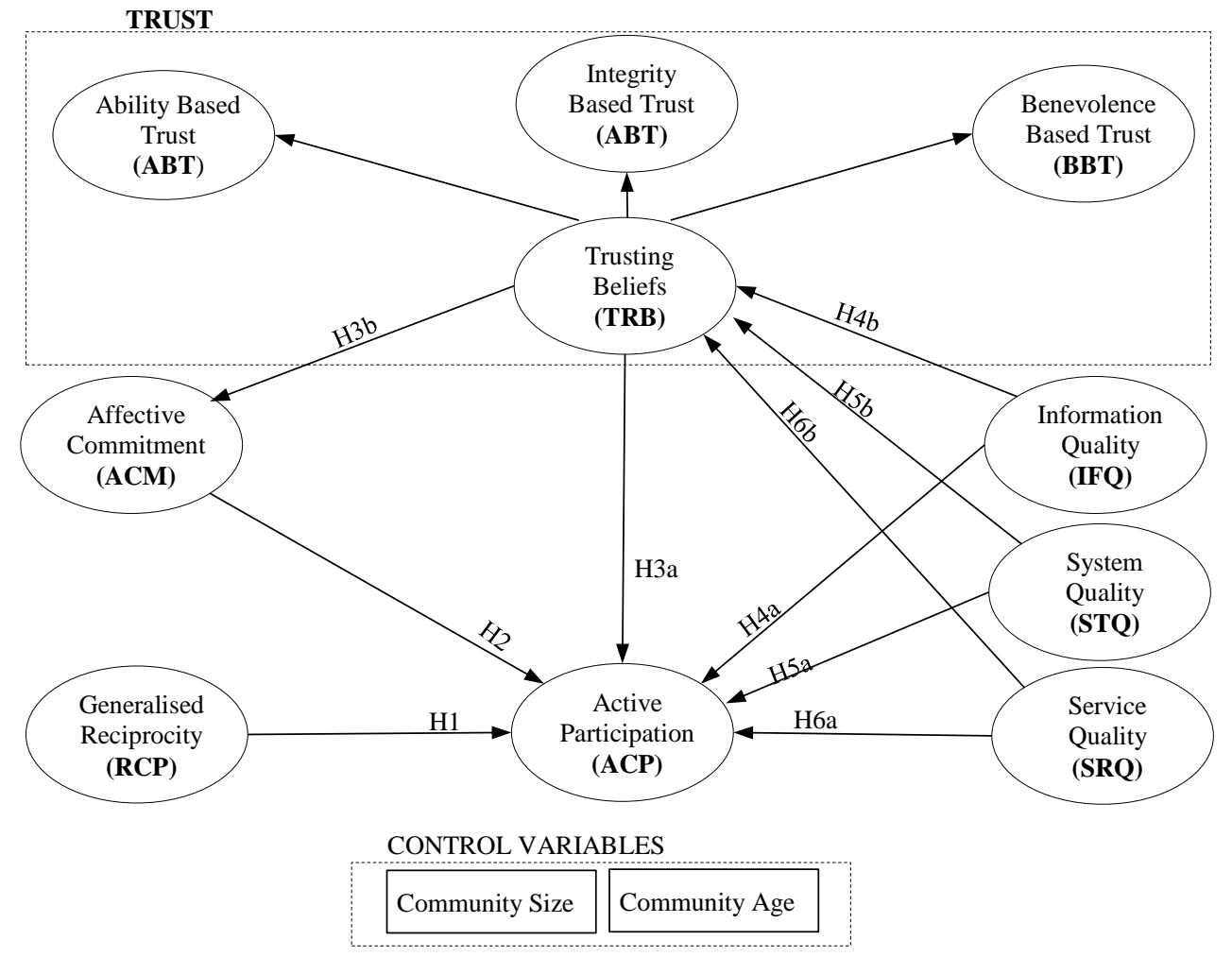

Figure 1: Proposed Framework

\subsection{Affective Commitment}

SET suggests that affective commitment is one of the key elements determining the outcomes of a B2B relationships in B2B OC, which ensures the relationship will continue in the future [62,63]. In a B2B relationship with higher affective commitment, participants are more likely to honour decisions and agreements that they make, to be open with one and other, and to share more information with one and other [81]. Accordingly, this study postulates that affective commitment positively influences active participation in B2B OC. This implies that in B2B OC, members who benefited greatly (e.g., received lots of help and advice from the community in the past) would develop stronger emotional attachment and a higher sense of belonging to the community and that makes it difficult for them to leave the community and as they therefore continue to actively participate in the community. Accordingly, this study hypothesizes that:

\section{H2: Affective commitment has a positive impact on members' active participation behaviour in B2B OC.}

\subsection{Trusting Beliefs}

SET suggests that trusting beliefs are a crucial element in social exchange [82]. The construct can be seen as a social bond in B2B relationships, which can determine the outcomes of the relationship [49,63]. In the context of B2B online community, trusting beliefs are very important because this type of online platform creates a risky atmosphere for its members [67]. Particularly, members who are business owners and managers might share information and interact with other members with whom they never meet or have had no prior interaction with. Hence, in B2B OC, members require some level of trust as businesses may be reluctant to share information or disclose such sensitive information with other businesses they don't trust. Specifically, disclosing one's business 
weaknesses and providing vital information can be used to harm the business [83]. Accordingly this study hypothesizes that in a B2B OC, members who have a higher belief in the ability, integrity and benevolence of other members will participate more actively. Evidence emphasising the importance of trusting beliefs for participation in various online community types is well documented in a large stream of empirical studies $[42,68,77,84,85]$. This study also postulates that trusting beliefs is positively related to affective commitment in B2B OC. The members of a B2B OC will be more emotionally attached and develop a higher sense of belonging to the community if trust is very high between the members. Perry et al. [63] posited that trust is a positive determinant of commitment. Morgan and Hunt [86] argued that parties are more willing to commit themselves to a relationship where trust is highly valued. Vatanasombut et al. [21] conducted a study to investigate IS continuance intention in web-based applications like $\mathrm{OC}$ and found a positive association between trust and commitment. Therefore, we postulate that:

\section{H3a: Trusting beliefs has a positive impact on members' active participation behaviour in B2B OC.}

H3b: Trusting beliefs has a positive impact on members' affective commitment in B2B OC.

\subsection{Information Quality}

Information quality was found to be one of the critical success factors for OC [80]. Various definitions and diverse attributes of the construct are reported in the literature [87-89]. Consistent with past research [79, 90], this study measures the information quality construct by several attributes related to the posted messages. These include accuracy, meaningfulness, relevancy, completeness, currency, and the format of posted messages $[10,79,90]$. We postulate that B2B online community members expect to obtain quality information from their communities and this will influence their decision to actively participate in the community. Particularly when community users' expectations are high they are unwilling to accept low quality information [91]. In B2B OC, members often may make decisions in their business environment based on the responses to their posted questions. Thus, low quality of information (i.e. outdated or inaccurate information) can be a deterrent factor for the members. On the positive side, high information quality could positively influence members' participation behaviour [80,92]. Moreover, we also hypothesize that information quality is positively related to trusting beliefs. In B2B OC, there is lack of face-to-face contact between the members, and therefore any information exchange may require accuracy, completeness, and currency. Thus, one may postulate that outdated, inaccurate, irrelevant, and incomplete data can be seen as a deterrent factor and makes members lose their trust in their B2B OC. A considerable amount of research examined the relationship between information quality and trust in e-commerce. However, little research has focused on the positive impact of information quality on trusting beliefs in OC settings. Therefore, we propose that:

\section{H4a: Information quality has a positive impact on members' active participation behaviour in B2B OC.}

H4b: Information quality has a positive impact on members' trusting beliefs in B2B OC.

\subsection{System Quality}

In this study system quality is described as the general characteristics of B2B OC websites such as usability, reliability, adaptability, stability, and security [79, 87, 93, 94]. The current literature provides contradictory information on how the construct might influence members' participation behaviour in OC. Wang and Fesenmaier [22] stated that the ease of communication of OC systems encourages members' contributions. A study by Preece et al. [18] collected data from various OC and revealed that usability is one of the top five reasons for lurking. On the other hand, several researchers discovered that usability issues were not the major factor affecting content contributions in OC [95]. These contradictory findings could be due to two main reasons. First, the construct may have different effects on participation depending on the community type. For example, in OC where the members have advanced IT skills because of their professions, system quality may not play an important role, whereas in OC where the members are less IT literate, then system quality could be seen as a crucial factor. Second, system quality may influence other factors (e.g., trust) rather than active participation itself and this is further supported by empirical research [69, 77]. Nicolaou and McKnight [96] found that system quality is an important factor for trust building in online interaction. A study by Ratnasingam [97] discovered that system quality increases trust in online environments. In their study McKnight et al. [69] developed and tested a model of consumer trust in an electronic ecommerce vendor. Their framework included system quality (e.g., website quality) as an antecedent factor for trusting beliefs. They further empirically tested their model and the result suggests that system quality is a powerful tool that vendors can use to increase consumer trust. Considering the lack of research in the area of B2B OC, it is important to investigate the system quality phenomenon in this context. Accordingly, this study hypothesizes that: 
H5a: System quality has a positive impact on members' active participation behaviour in B2B OC. H5b: System quality has a positive impact on members' trusting beliefs in B2B OC.

\subsection{Service Quality}

There is a lack of clear understanding of what exactly service quality means in the online community context. Our examination of the literature revealed that a large number of studies were unclear in distinguishing between service quality and information quality or system quality. Particularly most of the dimensions of service quality have also been identified as the dimensions of information quality or system quality [98-101]. According to Lee and Lin [100], in online environments like online shopping sites service quality focuses on web site design, reliability, responsiveness, trust, and personalisation. Further, Ho and Lee [101] identified five dimensions of e-service quality namely, information quality, security, website functionality, customer relationships and responsiveness. Yang et al. [99] developed an instrument to measure service quality in web portals which included the following dimensions: usability, usefulness of content, adequacy of information, and accessibility of information. In their study, Yang and Fang [98] carried out research to better understand service quality and customer satisfaction in online securities brokerage services. They identified 16 different dimensions of service quality, including accessibility, timeliness, security, ease of use, system reliability and flexibility. Accordingly, this study first explored the meaning of service quality in the context of B2B OC and found that the service quality was related to the services provided by moderators, not necessary by the community providers (e.g., preventing distribution in community and encouraging members to participate). The literature is also contradictory on how service quality may affect active participation in OC. Kuo [102] has identified service quality as one of the key predictors for members' intention to use OC. Elliot et al. [103] have emphasised the importance of service quality in OC and further found the construct to have a significant effect on members' satisfaction and trust. Similarly, Lin [104] found the construct to have a positive impact on user satisfaction and behaviour intention to use OC. Contrarily, some studies suggest that service quality does not apply to the online community context. For example, Lin [10] modelled system quality and information quality as the only two dimensions of information system success for OC. Having discovered limited and contradictory research focused on service quality in B2B OC, one could argue that it is quite important to investigate the phenomenon. In B2B OC, if the members find that their community is well- moderated then they will develop higher levels of trusting beliefs and will participate more actively in their community's activities. Considering lack of research on the impact of service quality on participation in B2B OC and consistent with the two previous hypotheses, this study postulates that:

H6a: Service quality has a positive impact on members' active participation behaviour in B2B OC. H6b: Service quality has a positive impact on members' trusting beliefs in B2B OC.

\section{Methodology}

To develop an in-depth understanding of the active participation phenomenon and to test our model, we used a combination of qualitative and quantitative research methods. First, we conducted twelve semi-structured interviews with B2B OC members and recorded and transcribed the interviews. We then applied thematic analysis and crosschecked the transcribed data and our coded themes with four academics in order to ensure our coding reliability. The qualitative study provided rich information which helped us to develop the measures for active participation and service quality in the context of B2B OC and to pilot test our questionnaire. Next, we carried out a quantitative study to test our proposed theoretical framework. The data for this study was collected over six weeks using an online survey administered to the members of 40 B2B discussion groups in LinkedIn. In total 4,500 invitation emails with a link to our survey were sent out. After three weeks a reminder was sent out. A total of 521 useable questionnaires were returned. Based on our objectives and the research model, the unit of analysis was the individual participants who were mainly owners or managers in business organisations. The respondent demographic data and business characteristics are shown in Tables $1 \& 2$.

We used variation of a wave analysis to check for non-response bias. Following previous studies [105, 106], we divided the sample into two groups: early responses (the first $10 \%$ of the sample) and late responses (the last $10 \%$ of the sample). We applied independent sample t-test and Chi-square tests using SPSS to compare the demographic data and business characteristics between the two groups. First we conducted t-test for age, position, and company size as these are ordinal variables. We then conducted Chi-square test for gender, education, and industry type because these are nominal variables. The results indicate that the non-response bias was not a significant issue for our study because 
there was no significant difference between the two groups. All the $\mathrm{p}$ values were greater than the significance level (e.g., $\mathrm{p} \leq 0.05)$.

Table 1: Respondents' Demographic Variables

\begin{tabular}{|c|c|c|c|}
\hline & $\mathrm{F}$ & $\%$ & $\begin{array}{c}\text { Early Vs. Late } \\
\text { Comparison } \\
\text { (P Value) }\end{array}$ \\
\hline \multicolumn{4}{|l|}{ Gender } \\
\hline Male & 373 & 71.6 & 0.475 \\
\hline Female & 148 & 28.4 & \\
\hline \multicolumn{4}{|l|}{ Age Group } \\
\hline $18-21$ & 4 & 0.8 & \multirow{7}{*}{0.764} \\
\hline $22-25$ & 31 & 6.0 & \\
\hline $26-30$ & 61 & 11.7 & \\
\hline $31-40$ & 148 & 28.4 & \\
\hline $41-50$ & 128 & 24.6 & \\
\hline $51-60$ & 102 & 19.6 & \\
\hline $61+$ & 47 & 9.0 & \\
\hline \multicolumn{4}{|l|}{ Education Background } \\
\hline School Certificate or equivalent & 22 & 4.2 & \multirow{7}{*}{0.224} \\
\hline GCSE/ O Levels or equivalent & 8 & 1.5 & \\
\hline AS/A Levels or equivalent & 29 & 5.7 & \\
\hline Bachelor Degree or equivalent & 213 & 40.9 & \\
\hline Master Degree or equivalent & 196 & 37.6 & \\
\hline $\mathrm{PhD}$ or equivalent & 24 & 4.6 & \\
\hline Others & 29 & 5.7 & \\
\hline
\end{tabular}

Table 2: Respondents' Business Characteristics

\begin{tabular}{|c|c|c|c|}
\hline & $\mathrm{F}$ & $\%$ & $\begin{array}{c}\text { Early Vs. Late } \\
\text { Comparison } \\
\text { (P Value) }\end{array}$ \\
\hline \multicolumn{4}{|l|}{ Industry type } \\
\hline Manufacturing & 53 & 10.2 & \multirow{6}{*}{0.099} \\
\hline Business Services & 298 & 57.2 & \\
\hline Financial Services & 35 & 6.7 & \\
\hline Retail & 27 & 5.2 & \\
\hline $\mathrm{R} \& \mathrm{D}$ & 36 & 6.9 & \\
\hline Others & 72 & 13.8 & \\
\hline \multicolumn{4}{|l|}{ Position } \\
\hline Staff & 53 & 10.2 & \multirow{5}{*}{0.147} \\
\hline Senior Staff & 118 & 22.6 & \\
\hline Manager & 108 & 20.7 & \\
\hline Director & 85 & 16.3 & \\
\hline $\mathrm{CEO}$ & 157 & 30.1 & \\
\hline \multicolumn{4}{|l|}{ Company size } \\
\hline $1-10$ & 304 & 58.3 & \multirow{5}{*}{0.767} \\
\hline $11-50$ & 84 & 16.1 & \\
\hline $51-250$ & 50 & 9.6 & \\
\hline $251-1000$ & 41 & 7.9 & \\
\hline Over 1000 & 42 & 8.1 & \\
\hline
\end{tabular}

\section{Measures}

Survey items used to measure the constructs in our model are provided in Appendix A. They are either adapted from existing scales or developed from the qualitative study. Items were measured in Likert scales anchored on " $1=$ strongly disagree" and "7 = strongly disagree". The measurement items for Generalised Reciprocity (RCP) were adapted from a prior study by Kankanhalli et al. [51]. Affective Commitment (ACM) measure was adapted from a prior study by Bateman et al. [61]. Three sub-constructs of Trusting Beliefs (TRB) namely: Ability Based Trust (ABT), Integrity Based Trust (IBT), and Benevolence Based Trust (BBT) were adapted from prior studies by McKnight et al. [69] and Ridings et al. [77]. Six items measured ABT, which focused on trusting other members' skills, knowledge, capabilities and performances in the B2B OC. Four items measured IBT, which focused on the other members' behaviour, fairness, trustworthiness, and honesty. Four items measured BBT which related to community members caring about helping other members, caring about the importance of others, and not taking advantage of other members or disturbing other members. Five items were used to measure Information Quality (IFQ) that reflected on the information accuracy, usefulness, completeness, currency, and format of information presentation. Five indicators were also used to measure System Quality (STQ) and these reflected on the reliability, accessibility, response time, and flexibility of community's website. All these indicators from both constructs were adapted from prior studies [79, 90, 107]. Five items were used to measure Service Quality (SRQ), and they reflected the moderator's role e.g., getting involved in solving problems and disputes, stopping disruptive members, and encouraging active participation. Six items were used to measure Active Participation (ACP), reflected on B2B OC members carrying out several activities such as login regularly, keeping their profile up-to-date, complying with the community rules and regulations, making quality posts such as posting questions that generate discussion, and replying to posed questions. The measures for SRQ and ACP were developed from our qualitative study.

\section{Data Analysis}

We used Structural Equation Modelling (SEM), covariance-based approach using AMOS for the main data analysis. We selected SEM because it is a second generation approach, which is seen as a more rational choice for 
our study. Specifically, our theoretical framework included several dependent variables (DV), which required us to conduct a series of regression analyses in a single test. Several techniques and programs such as LISERL, AMOS, EQS and PLS were used to perform SEM [108, 109]. Based on statistical algorithms, these were also divided into two categories: covariance-based approach (LISERL and AMOS) and partial-least-squares-based approach (EQS and PLS-Graph) [109]. Taking into consideration the primary aim of this study, the confirmatory (theory testing) nature of our research, and the sample size, a covariance-based approach was seen as a rational choice. PLS has been seen to be robust in the case of small sample sizes [105]. Our sample size was considerably large $(\mathrm{n}=521)$. Scholars have suggested that the degree of knowledge and time are the two important factors that researchers should consider in reaching a better decision when selecting an analysis technique [110]. Considering these factors, we decided to use AMOS as the main data analysis technique. The data analysis was performed in several stages. First, a preliminary data analysis in SPSS was carried out to ensure accurate and unbiased results. Next, an Exploratory Factor Analysis (EFA) in SPSS was conducted to assess the newly developed measures. This was followed by a Confirmatory Factor Analysis (CFA) in AMOS to validate the measurement model. In the final stage, the structural model was validated in AMOS.

\subsection{Confirmatory Factor Analysis}

Before conducting the CFA, several pre-data examinations were carried out to check accuracy and unbiased results. This included evaluating and treating for missing data, normality, co-linearity, outliers, and sample size. The missing data was treated with Expectation Maximisation. Our data was normally distributed as the SkewnessKurtosis $\mathrm{Z}$ score values for all the variables were within the accepted range $( \pm 2.58)[108,109]$. No issues with Collinearity were detected as the Variance Inflation Factor (VIF) values for all the independent variables were less than the threshold 4.0 [111]. Using the three standard deviation rule, we discovered that 39 cases had outliers on at least one of the indicators $[109,112,113]$. A further investigation revealed that the these records had very little impact on the CFA results and therefore they were retained in the subsequent analysis [113]. It was found that the sample size $(\mathrm{n}=521)$ was adequate.

An Exploratory Factor Analysis (EFA) in SPSS was conducted because two of the scales (ACP and SRQ) were newly developed and the measures for a number of other constructs (e.g., IFQ, STQ and TRB) were adopted from multiple sources. We performed a Principal Component Factor Analysis with a Promax rotation to validate the scales. Nine factors was extracted which together explained $73.6 \%$ of the total variance. The factor loadings for ACP5, ACP2, STQ1, SRQ1, and BBT1 were 0.33, 0.59, 0.40, 0.43, and 0.66 respectively, which was below the accepted threshold of 0.7 [109]. Further, it was discovered that IBT4 (-0.81) and STQ3 (-0.74) had negative loadings. The negative loadings indicates that the participants perceived the two questions related to IBT4 and STQ3 differently from the pertinent question groups (Integrity Based Trust and System Quality), and therefore they did not accurately measure their relevant constructs. Subsequently, they were eliminated from the scale. We reanalysed the scales and discovered two more items - STQ4 (0.66) and SRQ4 (0.69) - did not load strongly and therefore they were also deleted from the analysis. Subsequently, a satisfactory results was achieved. The final results of the EFA are shown in Appendix B.

Confirmatory Factor Analysis (CFA) was carried out to validate the measurement model. The reliability of each construct was assessed by examining the Cronbach's $\alpha$ value. Table 3 shows that none of the constructs had reliability issues as the values of Cronbach's $\alpha$ were all above the accepted threshold (0.7) [109]. Further, the convergent validity was assessed through examining the factor loadings of the items on to their associated constructs and the Average Variance Extracted (AVE). The measures had acceptable convergent validity as all item loadings were greater than 0.70 (See Appendix B) and all of the constructs had an AVE larger than 0.5 as shown in Table 3. Finally, we assessed the Discriminant Validity of the factors through comparing AVE with Squared Inter-construct Correlations (SIC) $[108,109]$. Table 3 shows the Discriminant Validity test results, which indicate adequate discriminant validity as all the AVE estimates were greater than the corresponding SIC.

Table 3: Reliability and Discriminant Validity Test Results

\begin{tabular}{|c|c|c|c|c|c|c|c|c|c|c|c|c|}
\hline & Mean & S.D & CA & IBT & $\mathrm{RCP}$ & ACP & ACM & IFQ & STQ & SRQ & ABT & BBT \\
\hline IBT & 4.44 & 0.88 & 0.89 & 0.74 & & & & & & & & \\
\hline $\mathrm{RCP}$ & 5.18 & 0.88 & 0.83 & 0.25 & 0.62 & & & & & & & \\
\hline ACP & 3.74 & 0.96 & 0.84 & 0.10 & 0.24 & 0.57 & & & & & & \\
\hline $\mathrm{ACM}$ & 3.19 & 1.11 & 0.95 & 0.21 & 0.20 & 0.21 & 0.78 & & & & & \\
\hline IFQ & 4.56 & 1.03 & 0.92 & 0.33 & 0.21 & 0.10 & 0.34 & 0.70 & & & & \\
\hline
\end{tabular}




\begin{tabular}{llllllllllll} 
STQ & 4.23 & 0.79 & 0.87 & 0.24 & 0.19 & 0.13 & 0.20 & 0.36 & $\mathbf{0 . 6 9}$ & $\mathbf{0 . 6 7}$ & \\
SRQ & 4.47 & 0.90 & 0.86 & 0.32 & 0.23 & 0.09 & 0.27 & 0.44 & 0.41 & 0.73 & $\mathbf{0 . 7 3}$ \\
ABT & 4.96 & 0.97 & 0.93 & 0.56 & 0.32 & 0.14 & 0.24 & 0.36 & 0.22 & 0.41 & 0.51 \\
BBT & 3.84 & 0.75 & 0.83 & 0.58 & 0.34 & 0.13 & 0.37 & 0.41 & 0.30 & 0.40 & $\mathbf{0 . 6 2}$ \\
\hline \multicolumn{2}{l}{ AVE are shown as bold in the diagonal of the table } & \multicolumn{2}{l}{ SIC are shown as normal in the columns and rows } & CA: Cronbach's Alpha & S.D: Std. Deviation
\end{tabular}

\subsection{Measurement Model Validation Results}

The measurement model consisted of seven main reflective constructs and a second-order factor "TRB", which was formed by the three sub-constructs: ABT, IBT, and BBT. We tested the measurement model in AMOS using Maximum Likelihood Estimation method. We used the following fit indices to determine the overall model fit: Normed Chi-Square (X²/df), Root Mean Square Error of Approximation (RMSEA), Standardised Root Mean Square (SRMR), Normed Fit Index (NFI), Incremental Fit Index (IFI), Tucker Lewis Index (TLI), and Comparative Fit Index (CFI). The measurement model evaluation test results indicated good model fit as all the obtained values for the fit indices were within the accepted range as shown in Table 4.

Table 4: Measurement model fit Test Results

\begin{tabular}{|c|c|c|}
\hline Fit Indices & Obtained Value & Recommended Threshold \\
\hline \multicolumn{3}{|c|}{$X^{2}=1276.223 d f=503 \quad p=0.000$} \\
\hline$X^{2} / d f$ & 2.54 & $\leq 3$ \\
\hline RMSEA & 0.05 & $\leq 0.08$ \\
\hline SRMR & 0.05 & $\leq 0.10$ \\
\hline NFI & 0.91 & $\geq 0.90$ \\
\hline IFI & 0.95 & $\geq 0.90$ \\
\hline TLI & 0.94 & $\geq 0.90$ \\
\hline CFI & 0.95 & $\geq 0.90$ \\
\hline
\end{tabular}

\subsection{Common Method Bias Assessment}

Following Podsakoff et al.'s [114] guidelines and several previous studies [115, 116], we performed two statistical analyses to test for Common Method Bias (CMB). First, the Harmon's single factor test on the nine constructs was conducted. An exploratory factor analysis with no rotation on one construct was conducted. The results indicated that the most variance explained by a single factor was about $42 \%$. Hence, Harman's test suggests that $\mathrm{CMB}$ was not a major issue in our study. Next we used the common latent factor approach to assess common variance among all the observed variables in our model. Two CFA tests were carried out using AMOS for two models. The first model included all the factors with all of the items each linked to associated latent factor. The fit indices for this model are shown in Table 4, which were all within the accepted thresholds. In the second model we included an additional factor: common latent factor. All the 34 items were linked to this additional factor as well as to their associated constructs. The fit indices for this model were as follows: $\mathrm{X}^{2}=1120.152, \mathrm{df}=502, \mathrm{p}=0.000$, $\mathrm{X}^{2} / \mathrm{df}=2.23, \mathrm{RMSEA}=0.05, \mathrm{SRMR}=0.05, \mathrm{NFI}=0.92, \mathrm{IFI}=0.96, \mathrm{TLI}=0.95$, and $\mathrm{CFI}=0.96$. Thus, they all satisfied the recommended thresholds for a good model fit. Upon examining the results of the two models, we found very minor difference between the fit indices and the path coefficients of the two models. Accordingly, we concluded that $\mathrm{CMB}$ was not a major issue in our data and therefore we proceeded to the next stage of the data analysis.

\subsection{Structural Model Validation Results}

The structural model was specified based on the theoretical model and tested in the same way as the measurement model [109]. Thus, the same fit indices were used to examine goodness fit of the model. The test results indicated good model fit as all the fit indices $-\mathrm{X}^{2}(1483.332)$, df (595), $\mathrm{p}(<0.001), \mathrm{X}^{2} / \mathrm{df}(2.50)$, RMSEA (0.06), SRMR (0.06), NFI (0.91), IFI (0.94), TLI (0.93), and CFI $=(0.94)$ - were within the accepted range. After achieving a satisfactory model, we then examined the causal relationships between the latent constructs. Figure 2 depicts the model test results and Table 5 shows further details on the hypotheses results. The research model explained a large amount of variance in the dependent variables. As shown in Figure 2, the model explained 66\% of the variance in trusting beliefs, $41 \%$ of the variance in affective commitment, and $32 \%$ of the variance in active participation. We carried out an effect size analysis using $\mathrm{G}^{*}$ Power V3.1 to determine the required sample [117]. Given the number of independent variables (6) and the sample size (521), effect size $\left(\mathrm{F}^{2}=0.47\right)$ as inputs, the results indicated that the statistical power of our study was above 0.99 , exceeding the recommended threshold of 0.80 for moderate and large effect size [118]. Thus, it was found that our sample size was large enough to test our research model. 
The analysis provided evidence supporting all the hypotheses identified under SET except for H3a. A positive relationship was found between RCP and ACP $(\mathrm{H} 1, \beta=0.34, \mathrm{p} \leq 0.001)$ and between ACM and ACP $(\mathrm{H} 2, \beta=0.30$, $\mathrm{p} \leq 0.001)$. However, the direct association between TRB and ACP was not significant (H3a, $\beta=0.08, p=0.42$ ). Nevertheless, a positive relationship between TRB and ACM (H3b, $\beta=0.64, p \leq 0.001)$ was detected, and this way $\mathrm{H} 3 \mathrm{~b}$ was accepted. The three sub-constructs (IFQ, STQ, and SRQ) of ISSM were found to be positively associated with TRB (H4b, $\beta=0.40, p \leq 0.001 ; H 5 b, \beta=0.11, p \leq 0.05 ; H 6 b, \beta=0.40, \leq 0.001$ ), and this evidence supported H4b, H5b, and H6b. There was also a positive relationship between STQ and ACP (H5a, $\beta=0.16, p \leq 0.05$ ). Surprisingly, H4a and H6a were rejected as both IFQ and SRQ were found to have no direct association with ACP (H4a, $\beta=-0.09, \mathrm{p}=0.25 ; \mathrm{H} 6 \mathrm{a}, \beta=-0.10, \mathrm{p}=0.124)$.

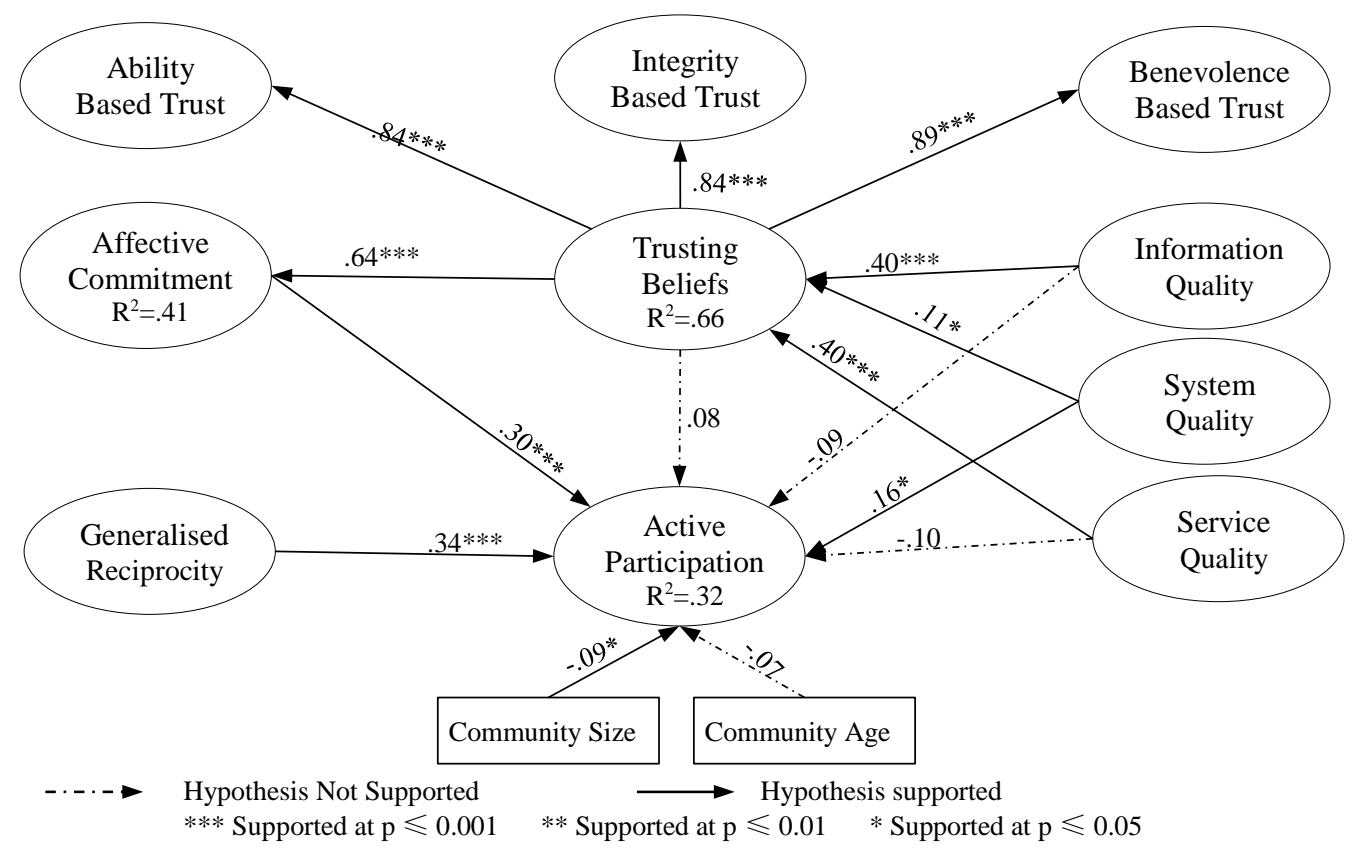

Figure 2: Hypotheses Test Results

Table 5: Hypotheses Test Results

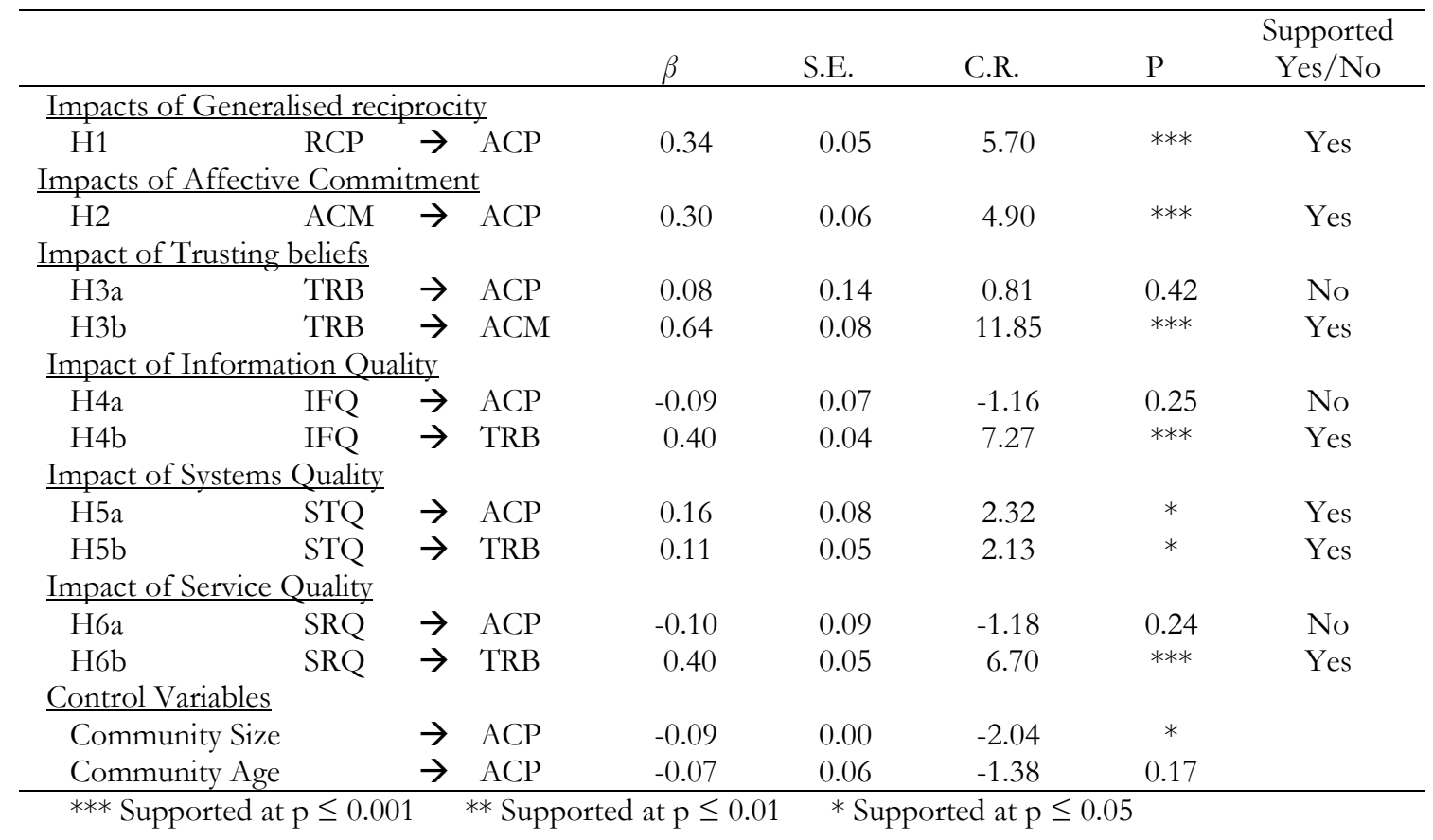

\subsection{Post Hoc Analysis}


We performed additional analyses to assess any mediation and moderation effects in the model. First we tested the mediating effect of ACM on the relationship between TRB and ACP. Following the guidelines of Preacher and Hayes [119] and previous studies [105, 106], using Boot Strapping strategy and bias-corrected technique, we explored the total as well as the direct and indirect effects of TRB on ACP [105]. Table 6 shows the results of the mediation analysis. Before ACM was included as a mediator, TRB had no direct impact on ACP $(\beta=0.21, p=0.08)$. When ACM was introduced as the mediator, TRB also did not have a direct effect on ACP $(\beta=0.08, p=0.42)$. However, the indirect effect of TRB on ACP through ACM was found to be significant $(\beta=0.19, \mathrm{p}<0.001)$. Furthermore, the total effect of TRB on ACP was also significant $(\beta=0.37, p<0.01)$. These results showed that ACM was partially mediating the relationship between TRB and ACP.

Moreover, we conducted multi-group SEM analysis in AMOS to examine the moderating effects of IFQ, STQ, and SRQ on the relationship between TRB and ACM. Following previous research [52, 120], the sample was categorised into two groups (low and high) according to the respondents' perceptions of the moderating variables: IFQ, STQ, and SRQ. For this, median split was employed in order to have adequate sample size [52, 120]. Separate structural models were built for the two sub-samples. We run two models (constrained and unconstrained) model for each of the quality factors and then then conducted a chi-square difference test between the two models. The results are shown in Table 6, which indicated that there was moderating effect in our model as a significant changes in the chi-square $\left(\Delta x^{2}=68.38, \mathrm{p}<0.001: \Delta x^{2}=82.15, \mathrm{p}<0.001 ; \Delta x^{2}=81.26, \mathrm{p}<0.001\right)$ between the constrained and unconstrained models were detected [121]. The impact of the moderating variables was explored by examining the difference between the paths for the sub-groups. As shown in Table 6, the path between TRB and ACM for the high IFQ sub-sample $(\beta=0.57, p<0.001)$ was stronger than the low IFQ sub-sample $(\beta=0.42, p<0.001)$. Similarly, in the high STQ sub-group $(\beta=0.59, \mathrm{p}<0.001)$, the relationship between TRB and ACM was slightly higher than the low STQ sub-group $(\beta=0.54, \mathrm{p}<0.001)$. The path between TRB and ACM was much stronger for the high SRQ group $(\beta=0.65, \mathrm{p}<0.001)$ than for the low SRQ group $(\beta=0.51, \mathrm{p}<0.001)$. To further investigate the direction and significant of the relationship between TRB and ACM at given levels of IFQ, STQ, and SRQ, we plotted the interactions and then conducted simple slope tests. The test results are shown in Appendix C, which further affirmed that the three quality factors strengthen the relationship between TRB and ACM.

\section{Table 6: Post Hoc Analyses Test Results}

Mediating effect of ACM on the relationship between TRB and ACP

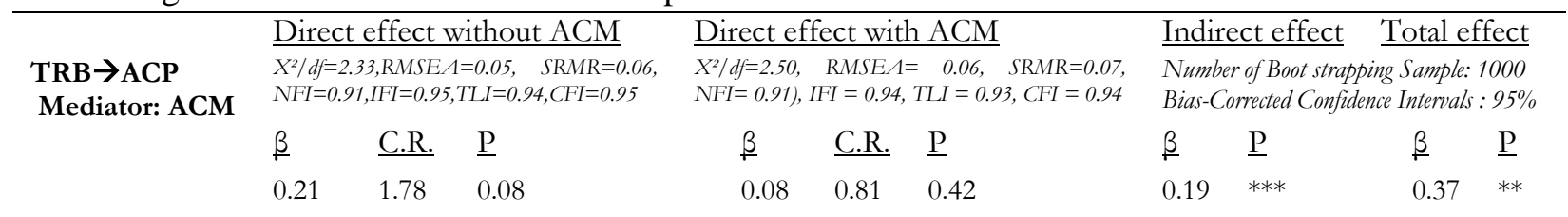

Moderating effects of IFQ, STQ, and SRQ on the relationship between TRB and ACM

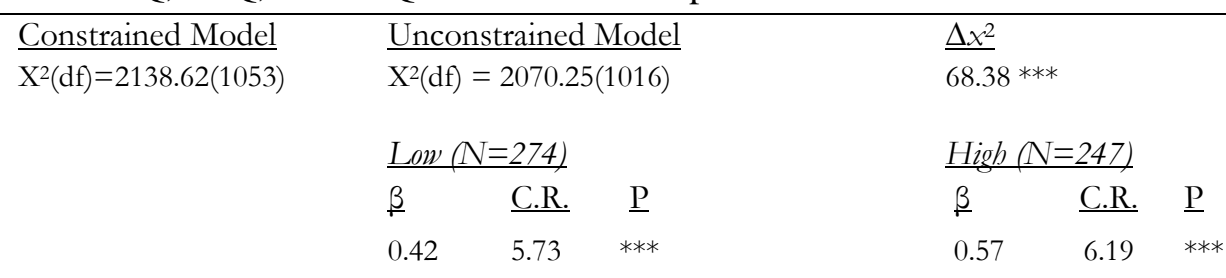

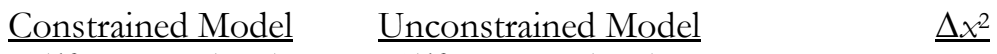

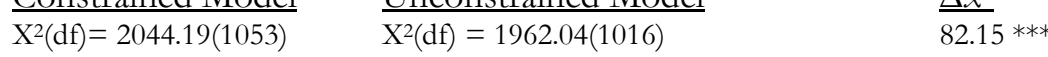

$\mathrm{TRB} \rightarrow \mathrm{ACM}$

Moderator: STQ

$\underline{\text { Constrained Model }}$ $\mathrm{X}^{2}(\mathrm{df})=2238.547(1053)$

\begin{tabular}{|c|c|c|}
\hline \multicolumn{3}{|c|}{$\underline{\operatorname{Low}}(N=251)$} \\
\hline$\underline{\beta}$ & $\underline{\text { C.R. }}$ & $\underline{P}$ \\
\hline 0.54 & 7.00 & $* * *$ \\
\hline
\end{tabular}

$\underline{\text { Unconstrained Model }}$ $\mathrm{X}^{2}(\mathrm{df})=2157.29(1016)$

$\mathrm{TRB} \rightarrow \mathrm{ACM}$ Moderator: SRQ

\begin{tabular}{lll}
\multicolumn{2}{l}{$\operatorname{Low}(N=280)$} & \\
$\underline{\beta}$ & $\underline{\text { C.R. }}$ & $\underline{P}$ \\
0.51 & 7.04 & $* * *$
\end{tabular}

\begin{tabular}{|c|c|}
\hline \multicolumn{2}{|c|}{ High $(N=270)$} \\
\hline$\underline{\beta}$ & $\underline{\text { C.R. }}$ \\
\hline 0.59 & 7.21 \\
\hline
\end{tabular}

$\underline{\Delta x^{2}}$

$81.26^{* * *}$

$\frac{\operatorname{High}(N=241)}{\underline{\beta} \quad \underline{\text { C.R. }} \quad \underline{\mathrm{P}}}$

*** Significant at $p \leq 0.001 \quad * *$ Significant at $p \leq 0.01 \quad *$ Significant at $p \leq 0.05$ 


\section{Discussion}

Our results reveal a number of interesting findings. Generalised reciprocity and affective commitment are positively associated with active participation in B2B OC. This finding is consistent with past research [20, 49] suggesting that OC members who have a higher belief in generalised reciprocity, a higher level of emotional attachment and sense of belonging will participate more actively. Different to our expectation and the outcomes of past research [29, 122], the direct relationship between trusting beliefs and active participation is not significant. However, the construct is still seen vital for the development of B2B OC. Trusting beliefs has a positive impact on affective commitment as predicted [123] and also has an indirect effect on active participation via affective commitment. This finding indicates that B2B OC members who develop a higher level of trusting belief will develop a higher sense of belonging and a higher emotional attachment and connection to the community, which ultimately leads to them becoming actively involved in the activities of the community. Thus, trusting belief is still vital for the development of B2B OC. Contrary to the results of past studies [80, 124], we find no direct relationship between information quality and active participation. Nevertheless, the construct is found to be a strong predecessor for trusting beliefs. Furthermore, the construct is also found to moderate the relationship between trusting beliefs and affective commitment. These findings indicate that information quality is still crucial for active participation in B2B OC. System quality has a positive impact on both active participation and trusting beliefs. Additionally the construct has a positive effect on the relationship between trusting beliefs and affective commitment. Hence, our results provide empirical evidence emphasising the importance of system quality in B2B OC in line with past research [22, 77]. Similarly, evidence supporting the importance of service quality in B2B OC is also found. The direct relationship between service quality and active participation was not significant, yet the construct was positively associated with trusting beliefs. Service quality is also found to have a positive impact on the relationship between trusting beliefs and affective commitment. Finally, within control variables, only community size is found to have a negative impact on active participation in B2B OC. This finding implies that in a smaller B2B OC group members may get to know each other better than in larger B2B OC, hence will participate more actively.

\subsection{Theoretical Contributions}

This research is among few studies that have explored active participation in the context of B2B OC. Thus it advances the theoretical development in this field and adds to the existing literature by further enhancing the understanding of key factors affecting active participation in B2B OC. Our study makes several significant contributions to OC research.

Firstly, our research contributes to the OC participation literature by theorising the active participation phenomenon in OC. A validated theoretical model on the factors affecting members' participation behaviour in B2B OC is proposed. The model integrates two different theories covering social and technical factors affecting active participation. The results demonstrate the appropriateness and robustness of our proposed model, which can provide a foundation and guidance for future studies by highlighting the need for more integrative theoretical approaches while offering model factors for further exploration. More specifically, despite numerous studies having examined the antecedents of participation in various OC types [4, 15, 24, 27, 32, 61, 95, 125], few have focused on B2B OC, which are different from other OC types because the members are mostly business owners and managers who have joined for their business purposes rather than for their personal needs.

Secondly, previous studies in this area mainly focused on social, cognitive, motivational and contextual factors, [e.g., 20, 35, 40, 42, 49, 51, 52]. In response to a recent study that found there to be a lack of attention to technological factors amongst OC scholars [50], our model reveals that technological-related factors are also crucial for increasing active participation in OC. The outcome of our model contradicts the view of OC scholars (e.g., Yang [95]) who suggest that technological factors is no longer a major factor affecting people's participation behaviour in OC.

Thirdly, our work contributes to OC research by developing a comprehensive and validated measure for active participation. This provides a new tested instrument for researchers to adapt in OC research, particularly B2B OC. Most prior studies on participation in OC $[17,18,41,46]$ utilised the number of posts, the number of replies, and the time spent browsing as indicators to measure participation in OC. However, our study has revealed that the measure of active participation in OC should also include quality elements. Accordingly, this research can be seen as a response to studies highlighting the need for better measures for OC participation [48, 49]. 
Fourthly, our findings extend existing knowledge on trust and commitment in OC. Our research suggests that it is important for scholars to pay greater attention to the multi-dimensional aspect of the two concepts when investigating participation phenomenon in OC. Our study shows that the applicability and importance of the many types of commitment (e.g., continuance, normative, and affective) and trust (e.g., disposition trust, trusting beliefs and system trust) vary from one community type to another. Most studies have viewed trust and commitment as unidimensional constructs [126], failing to capture their multi-dimensional aspects. Furthermore the final outcomes of our model suggests that the relationship between trust and commitment in OC is more complex than examined in prior studies $[63,85,86]$. The post hoc analysis revealed that affective commitment mediates the relationship between trusting beliefs and active participation. This implies that in B2B OC if the members are satisfied with the ability, integrity and benevolence of each other, then they will develop a higher sense of belonging and attachment to the community and that will encourage them to stay active. Although studies have examined the mediating effects of commitment on the relationship between trust and customer satisfaction in online business communities [127], very few have examined how affective commitment may mediate the relationship between trust and participation in OC. Recognising the mediating role of commitment contributes to the prior understanding of OC participation by revealing the underlying mechanism of how commitment and trust may impact the participation behaviour of OC members. Additionally, the post hoc analysis also discovers that information quality, system quality and service quality positively moderate the relationship between trusting beliefs and affective commitment. This indicates that in B2B OC, where the quality of the posted information is high, where the community website is of high quality, and where the community is well-moderated, the relationship between trusting beliefs and affective commitment is also higher. To the best of our knowledge these moderating effects are yet to be examined in the OC literature.

Lastly, this study offers interesting theoretical insights into service quality in the online community context. Our study not only discovers that service quality is crucial for the development of $\mathrm{OC}$, but also reveals that its definition differs in the OC literature. Previous studies suggest that service quality relates to services provided by the platform providers [128]. However, our study shows that service quality in OC is more concerned with services provided by in-group moderators, but not necessary by the platform providers. Our review of the literature discovered that scholars have paid little attention to how moderation influences participation in OC. One study highlighted the importance of moderators in OC, but provided no empirical evidence [61]. Furthermore, past research [107], only utilised system quality and information quality from the ISSM when investigating the participation phenomenon in OC, and therefore excluded service quality.

\subsection{Practical Implications}

The results of our research provide valuable practical guidelines for the owners and managers of B2B OC. This study demonstrates that generalised reciprocity, trusting beliefs, and affective commitment affect active participation. Further, it also emphasises the importance of the three quality factors (information quality, system quality, and service quality) for development of B2B OC.

In our study, the active participants who had high beliefs in generalised reciprocity were more active in their communities. Hence, they were more eager to provide support and help to other members if they believed they would be helped in the future. Members were willing to return the value they had obtained from the community to other members and this was seen as crucial for an on on-going affective relationship. Thus, it is important for B2B OC managers and moderators to develop strategies that improve the members' perceptions on the benefits that they gain from the community. Therefore we suggest community managers encourage reciprocal participation by regularly reminding members about the help they received from other members and continuously encouraging them to provide help and support to other members in need. Developing such reciprocal awareness among community members may therefore be a vital step that not only boosts active participation in the community, but also ensures a long-term sustainable relationship between members.

Affective commitment not only positively influences active participation, but also mediates the relationship between trusting beliefs and active participation. Participants who feel a strong sense of connection and strong sense of belonging to communities are more actively engaged in their community's activities. This accentuates that affective commitment is a crucial component for successful OC. Therefore we suggest that B2B OC managers find ways to increase their members' affective commitment. Furthermore, it is also equally important for community managers to find ways to increase the level of trusting beliefs between community members. One might argue that affective commitment or trusting beliefs may be difficult to develop and foster in OC, particularly at a large scale [61]. However, this might be achievable through developing affective relationship with the members, encouraging 
high quality contribution (e.g., information quality), having an effective website (system quality) as well as an effective moderation mechanism (service quality) [56]. Accordingly, it is important to ensure that posted messages are always up-to-date, accurate, relevant to the community, and presented in an aesthetically relevant format. Incorporating a rating mechanism may be effective in that regard. Other suggestions would be to continuously raise members' awareness about the importance of the quality of posting, set clear guidelines, frequently monitor posted messages and remove messages that are not relevant to the community. Our study also suggests that it is important for B2B OC owners to ensure that their community website is easy to use, easy to navigate, and trustworthy. Particularly, it would be essential for community owners to regularly elicit feedback from the members on their experience with the website and make changes to the features and functionalities of the community's website whenever necessary. Most importantly, we highly recommend that community managers not only acknowledge the moderator's contributions but also encourage them to get more involved in the community activities and recruit more moderators from experienced community members.

\subsection{Limitation and Future Research}

This study has several limitations that need to be addressed in future research. Although the study has followed the common practice of sampling in data collection and achieved a large data set, it is important to mention some sampling issues associated with data collection. Our sample appears to have a gender bias in that the vast majority of the participants were male. Further, a large proportion of the respondents were from service sector micro businesses. In addition, the sample was drawn from B2B OC on LinkedIn and data was collected from members who had some visible activities and whose profile was available to the public. All these sampling bias-related issues limit the generalisation of the outcomes of our study. Accordingly, future research should be conducted to test our model with other B2B OC that use different online platforms such as vBulletin, iPBoard, phpBB, and SMF. Moreover, the measure for the dependent variable (active participation) was primarily developed from a small sample size consisting of twelve participants. While the results of validity and reliability tests provided sufficient confidence, further validation is desirable based on a larger and more representative sample. Thus, there is an opportunity to further validate the measure for active participation in other OC environments.

\section{Conclusion}

This study develops and tests a research model drawing upon two well-known theories (SET and ISSM) to examine the antecedent factors affecting active participation in B2B OC. The empirical results indicate that generalised reciprocity and affective commitment are strong predictors for active participation. Trusting beliefs are found to have no direct impact on active participation, yet empirical results highlight the importance of trusting beliefs in B2B OC, since the construct is found to have a direct impact on affective commitment and indirect influence on active participation. The three constructs - information quality, system quality and service quality - identified under the ISSM are seen as important elements of B2B OC. Our study makes several significant contributions to OC research and practice. It also provides directions for future research.

\section{Acknowledgement}

We would like to thank the associate editor and the two anonymous reviewers for their constructive suggestions to improve the paper. We would like also to thank University of Bedfordshire, Luton Borough Council, Bedfordshire Borough Council, and Central Bedfordshire Council for funding this research project. 


\section{Appendices}

\section{Appendix A: Summary of Model Constructs and Measurement Scales}

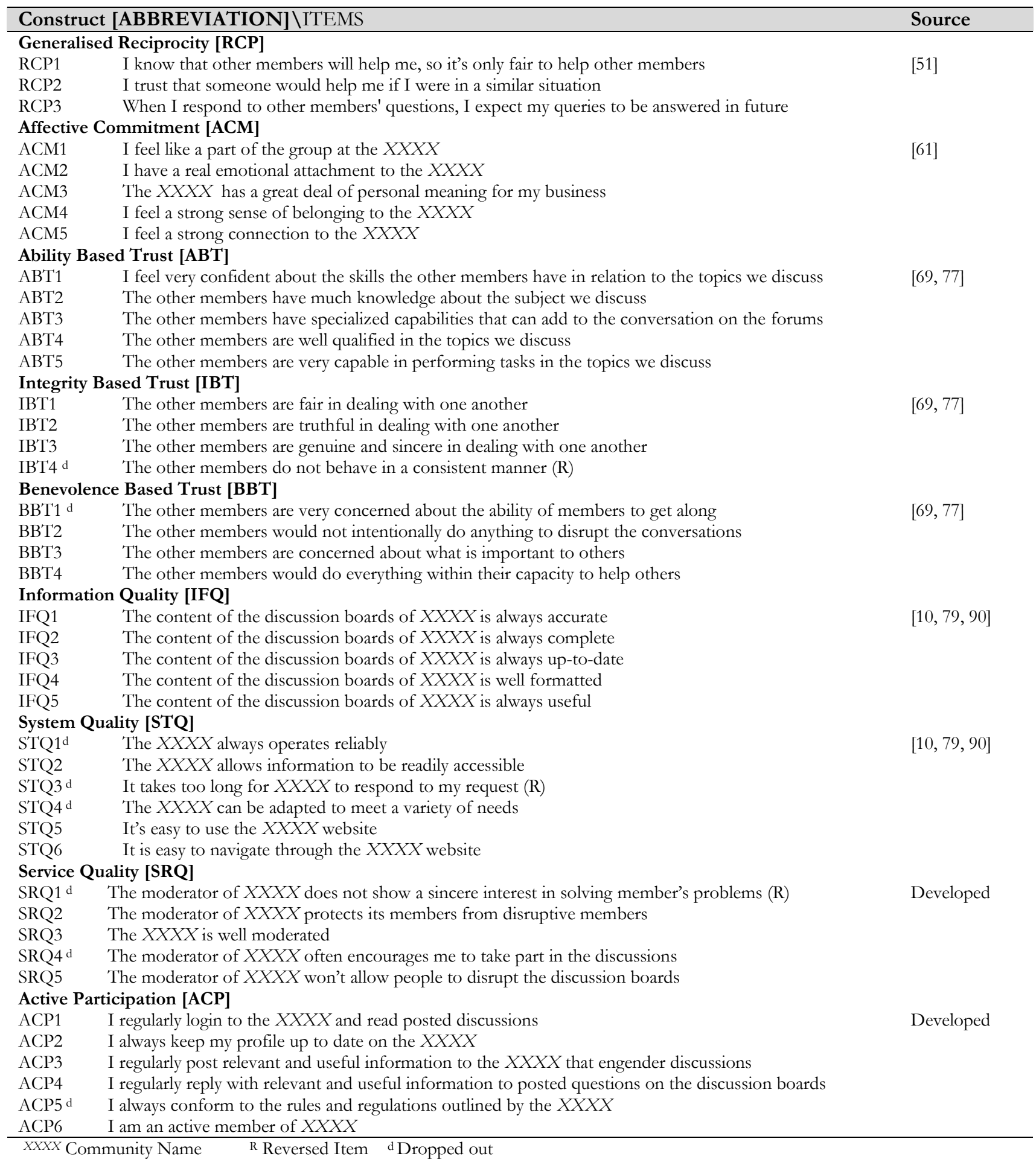


Appendix B: Items Loading and cross Loading

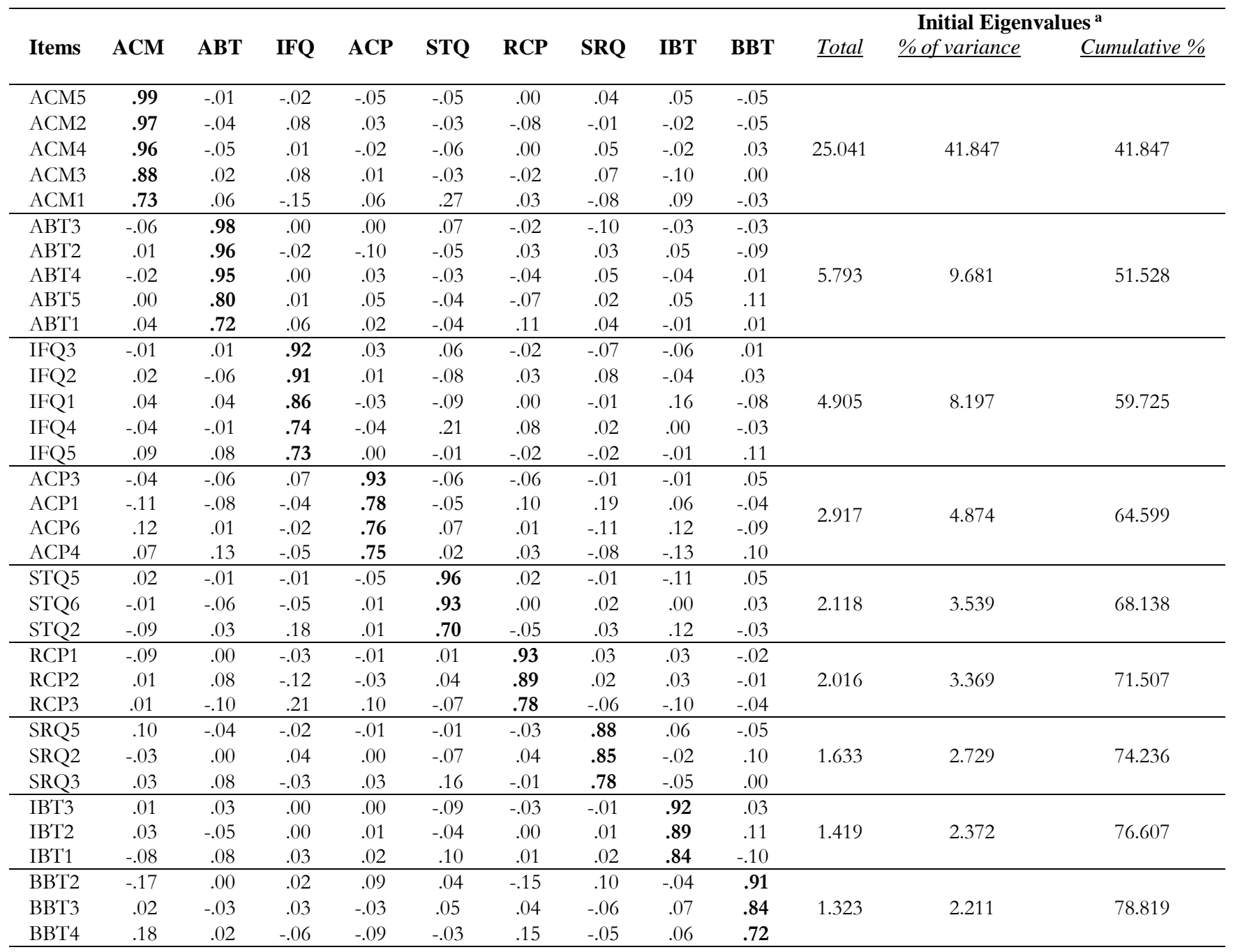

\section{Appendix C: Simple Slope Analysis}

To further examine the direction and significant of the relationship between TRB and ACM at given levels of IFQ, STQ, and SRQ, we plotted the interactions following the recommendations by Cohen and Cohen [129] (see Figures 3a to 3c). We then conducted simple slope tests using Aiken and West's [130] procedure. For the purpose of the simple slope test we divided the moderators (IFQ, STQ, and SRQ) into a high group (1 standard deviation greater than the mean) and a low group (1 standard deviation less than the mean). The results indicated that the three quality factors strengthen the relationship between TRB and ACM. Specifically, the simple slope of the regression of ACM onto TRB for high level of IFQ group ( 1 standard deviation above the mean) (slope $=0.67, t=7.45, p<0.001$ ) was greater than for low level of IFQ group ( 1 standard deviation below the mean) (slope $=0.49, t=7.06, p<0.001$ ). This is depicted in Figure 3a. The simple slope for the high level STQ group ( than the low level STQ group (slope $=0.54, \mathrm{t}=11.40, \mathrm{p}<0.001$ ) and this is apparent in Figure 3b. Finally, the test results revealed that the simple slope of the regression of ACM onto TRB for high level of SRQ (slope $=0.62, t=12.77$, $\mathrm{p}<0.001$ ) was much higher than the low level of SRQ (slope $=0.49, \mathrm{t}=12.04, \mathrm{p}<0.001$ ) and this is shown in Figure $3 \mathrm{c}$. 


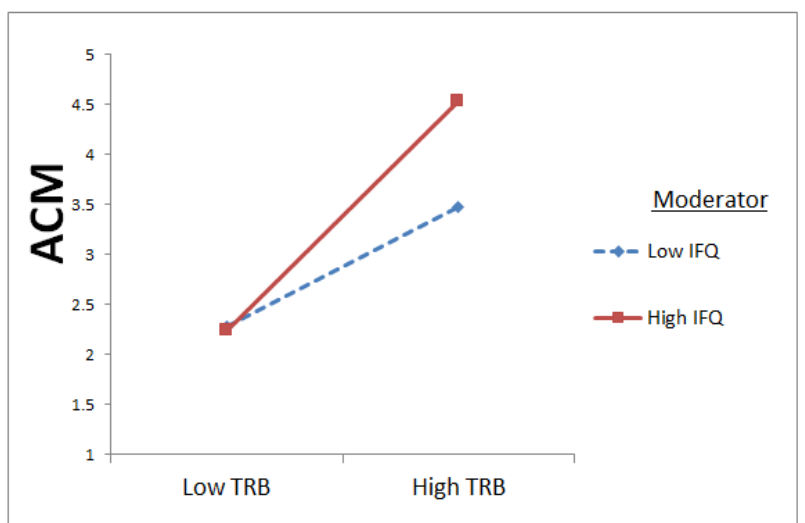

Figure3a: Moderating effect of IFQ on the relationship between TRB and ACM

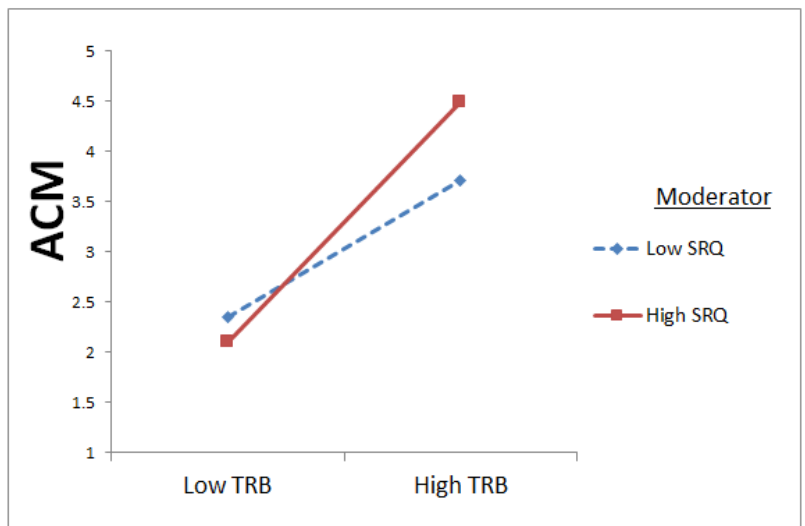

Figure3c: Moderating effect of SRQ on the relationship between TRB and ACM

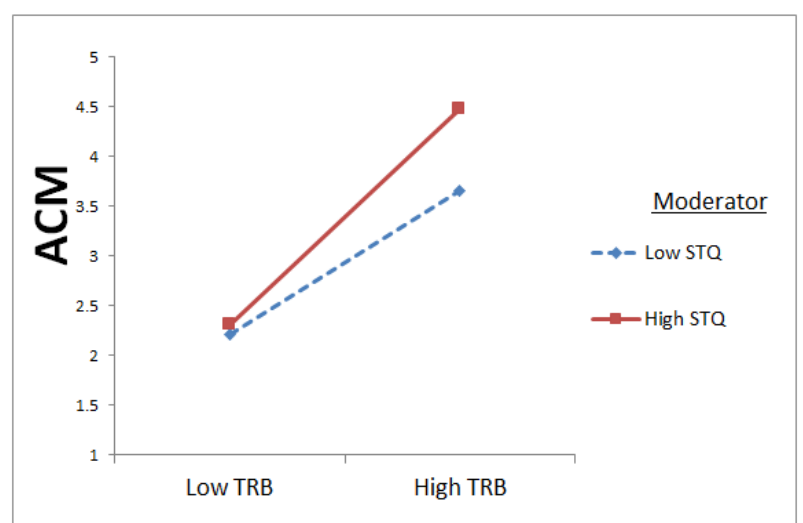

Figure3b: Moderating effect of STQ on the relationship between TRB and ACM

\section{References}

1. Erat, P., K.C. Desouza, A. Schafer-Jugel, and M. Kurzawa, Business Customer Communities and Knowledge Sharing: Exploratory Study of Critical Issues, European Journal of Information Systems, 2006, 15(5), pp. 511-524.

Hagel, J. and A. Armstrong, G, Net Gain: Expanding Markets through Virtual Communities, 1997: Harvard Business School Press. 235.

3. Koh, J. and Y.G. Kim, Knowledge Sharing in Virtual Communities: An E-Business Perspective, Expert Systems with Applications, 2004, 26(2), pp. 155-166.

4. Rishika, R., A. Kumar, R. Janakiraman, and R. Bezawada, The Effect of Customers' Social Media Participation on Customer Visit Frequency and Profitability: An Empirical Investigation, Information Systems Research, 2013, 24(1), pp. 108-127.

5. Chiu, C.-M., M.-H. Hsu, and E.T.G. Wang, Understanding Knowledge Sharing In Virtual Communities: An Integration of Social Capital and Social Cognitive Theories, Decision Support Systems, 2006, 42(3), pp. 1872-1888.

6. Bieber, M., D. Engelbart, R. Furuta, S.R. Hiltz, J. Noll, J. Preece, E. A. Stohr, M. Turoff, and B.V.D. Walle, Toward Virtual Community Knowledge Evolution, Journal of Management Information Systems, 2002, 18(4), pp. 11-35.

7. Hughes, T., N. O'Regan, and M.A. Sims, The Effectiveness of Knowledge Networks: An Investigation of Manufacturing SMEs, Education + Training, 2009, 51(8/9), pp. .665- 681.

8. Miller, N.J., T. Besser, and A. Malshe, Strategic Networking Among Small Businesses in Small US Communities, International Small Business Journal, 2007, 25(6), pp. 631-665.

9. Fuller-Love, N. and E. Thomas, Networking in Small Manufacturing Firms, Journal of Small Business and Enterprise Development, 2004 11(2), pp. 244-253.

10. Lin, H.-F., Determinants of successful virtual communities: Contributions from system characteristics and social factors, Information \& Management, 2008, 45(8), pp. 522-527.

11. Kim, J.W., J. Choi, W. Qualls, and K. Han, It Takes a Marketplace Community to Raise Brand Commitment: The Role of Online Communities, Journal of Marketing Management, 2008, 24(3), pp. 409-431.

Kordzadeh, N., C. Zhechao Liu, Y.A. Au, and J.G. Clark, A Multilevel Investigation of Participation Within Virtual Health Communities, Communications of the Association for Information Systems, 2014, 34(1), pp. 493-512.

13. Zhou, Z., Y. Fang, D.R. Vogel, X.-L. Jin, and X. Zhang, Attracted to or Locked In? Predicting Continuance Intention in Social Virtual World Services, Journal of Management Information Systems, 2012, 29(1), pp. 273-306.

14. Koh, J., Y.-G. Kim, B. Butler, and G.-W. Bock, Encouraging Participation in Virtual Communities, Communications of the ACM 2007, 50(2), pp. 68-73.

15. Ardichvili, A., V. Page, and T. Wentling, Motivation and Barriers to Participation in Virtual Knowledge-Sharing Communities of Practice, Journal of Knowledge Management, 2003, 7(1), pp. 64-77.

16. Wang, Y. and D.R. Fesenmaier, Modeling Participation in an Online Travel Community, Journal of Travel Research, 2004, 42(3), pp. 261-270. 
Sun, N., P.P.-L. Rau, and L. Ma, Understanding Lurkers in Online Communities: A Literature Review, Computers in Human Behavior, 2014, 38, pp. 110-117.

Preece, J., B. Nonnecke, and D. Andrews, The Top Five Reasons for Lurking: Improving Community Experiences for Everyone, Computers in Human Behavior, 2004, 20(2), pp. 201-223.

19. Lin, H.-F., The Role of Online and Offline Features in Sustaining Virtual Communities: An Empirical Study, Internet Research, 2007, 17(2), pp. 119 - 138.

Ray, S., S.S. Kim, and J.G. Morris, The Central Role of Engagement in Online Communities, Information Systems Research, 2014, 25(3), pp. 528-546.

Vatanasombut, B., M. Igbaria, A.C. Stylianou, and W. Rodgers, Information Systems Continuance Intention of Web-Based Applications Customers: The Case of Online Banking, Information \& Management, 2008, 45(7), pp. 419-428.

Wang, Y. and D.R. Fesenmaier, Towards Understanding Members' General Participation in and Active Contribution to an Online Travel Community, Tourism Management, 2004, 25(6), pp. 709-722.

Zhang, J., Voluntary Information Disclosure On Social Media, Decision Support Systems, 2015, 73(0), pp. 28-36.

Phang, C.W., C. Zhang, and J. Sutanto, The Influence of User Interaction and Participat
Intention of Niche Products, Information \& Management, 2013, 50(8), pp. 661-672.

Kordzadeh, N., C.Z. Liu, Y.A. Au, and J.G. Clark, A Multilevel Investigation of Participation Within Virtual Health Communities, Communications of the Association for Information Systems, 2014, 34(1), pp. 493-512.

Ba, S. and L. Wang, Digital Health Communities: The Effect of Their Motivation Mechanisms, Decision Support Systems, 2013, 55(4), pp. $941-947$.

Zhang, C., J. Hahn, and P. De, Research Note-Continued Participation in Online Innovation Communities: Does Community Response Matter Equally for Everyone?, Information Systems Research, 2013, 24(4), pp. 1112-1130.

Füller, J., K. Hutter, J. Hautz, and K. Matzler, User Roles and Contributions in Innovation-Contest Communities, Journal of Management Information Systems, 2014, 31(1), pp. 273-308.

Casaló, L.V., C. Flavián, and M. Guinalíu, Promoting Consumer's Participation in Virtual Brand Communities: A New Paradigm in Branding Strategy, Journal of Marketing Communications, 2007, 14(1), pp. 19-36.

Goes, P.B., M. Lin, and C.-m. Au Yeung, "Popularity Effect" in User-Generated Content: Evidence from Online Product Reviews, Information Systems Research, 2014, 25(2), pp. 222-238.

Cheung, C.M.K. and M.K.O. Lee, What Drives Consumers to Spread Electronic Word Of Mouth in Online Consumer-Opinion Platforms, Decision Support Systems, 2012, 53(1), pp. 218-225.

Huang, Q., R.M. Davison, and H. Liu, An Exploratory Study of Buyers' Participation Intentions in Reputation Systems: The Relationship Quality Perspective, Information \& Management, 2014, 51(8), pp. 952-963.

Ku, Y.-C., C.-P. Wei, and H.-W. Hsiao, To Whom Should I Listen? Finding Reputable Reviewers in Opinion-Sharing Communities, Decision Support Systems, 2012, 53(3), pp. 534-542. Evaluations, Information \& Management, 2015, 52(3), pp. 305-316.

Sun, Y., Y. Fang, and K.H. Lim, Understanding Knowledge Contributors' Satisfaction in Transactional Virtual Communities: A CostBenefit Trade-Off Perspective, Information \& Management, 2014, 51(4), pp. 441-450.

Sun, Y., Y. Fang, and K.H. Lim, Understanding Sustained Participation in Transactional Virtual Communities, Decision Support Systems, 2012, 53(1), pp. 12-22.

Tong, Y., X. Wang, C.-H. Tan, and H.-H. Teo, An Empirical Study of Information Contribution to Online Feedback Systems: A Motivation Perspective, Information \& Management, 2013, 50(7), pp. 562-570.

Nonnecke, B., J. Preece, and D. Andrews. What Lurkers and Posters Think of Each Other. in Proceedings of the 37th Annual Hawaii International Conference on System Sciences. 2004. Nonnecke, B. and J. Preece, Why lurkers lurk., in Americas Conference on Information Systems. 2001.

Zhao, K., A.C. Stylianou, and Y. Zheng, Predicting Users' Continuance Intention in Virtual Communities: The Dual IntentionFormation Processes, Decision Support Systems, 2013, 55(4), pp. 903-910.

41. Nonnecke, B., D. Andrews, and J. Preece, Non-Public and Public Online Community Participation: Needs, Attitudes and Behavior, Electronic Commerce Research, 2006, 6(1), pp. 7-20.

Chen, C.-J. and S.-W. Hung, To Give or to Receive? Factors Influencing Members' Knowledge Sharing and Community Promotion in Professional Virtual Communities, Information \& Management, 2010, 47(4), pp. 226-236.

Takahashi, M., M. Fujimoto, and N. Yamasaki, The Active Lurker: A New Viewpoint for Evaluating the Influence Of an In-House Online Community, SIGGROUP Bull., 2002, 23(3), pp. 29-33.

44. Golder, S.A. and J. Donath, Social Roles in Electronic Communities, Internet Research, 2004, 5(1), pp. $19-22$.

45. Arguello, J., B.S. Butler, E. Joyce, R. Kraut, K.S. Ling, C. Ros, and X. Wang, Talk to Me: Foundations for Successful Individual-Group Interactions in Online Communities, in Proceedings of the SIGCHI Conference on Human Factors in Computing Systems. 2006, ACM: Canada. p. 959-968.

Rafaeli, S., G. Ravid, and V. Soroka. De-Lurking in Virtual Communities: A Social Communication Network Approach to Measuring the Effects of Social and Cultural Capital. in System Sciences, 2004. Proceedings of the 37th Annual Hawaii International Conference on. 2004. 
Lee, M.K.O., C.M.K. Cheung, K.H. Lim, and C.L. Sia, Understanding Customer Knowledge Sharing in Web-Based Discussion Boards: An Exploratory Study, Internet Research, 2006, 16(3), pp. 289 - 303.

49. Lu, Y. and D. Yang, Information Exchange in Virtual Communities Under Extreme Disaster Conditions, Decision Support Systems, 2011, 50(2), pp. 529-538.

50. Pan, Y., Y. Xu, X. Wang, C. Zhang, H. Ling, and J. Lin, Integrating Social Networking Support for Dyadic Knowledge Exchange: A Study in a Virtual Community of Practice, Information \& Management, 2015, 52(1), pp. 61-70.

51. Kankanhalli, A., B.C.Y. Tan, and W. Kwok-Kee, Contributing Knowledge to Electronic Knowledge Repositories: An Empirical Investigation, Management Information Systems Quarterly, 2005, 29(1), pp. 113-143.

Tsai, H.-T. and R.P. Bagozzi, Contribution Behavior in Virtual Communities: Cogntiive, Emotional, and Social Influences Management Information Systems Quarterly, 2014, 38(1), pp. 143-163.

Chai, S., S. Das, and H.R. Rao, Factors Affecting Bloggers' Knowledge Sharing: An Investigation Across Gender, Journal of Management Information Systems 2011, 28(3), pp. 309 - 342

Hsu, C.-L. and J.C.-C. Lin, Acceptance of Blog Usage: The Roles of Technology Acceptance, Social Influence and Knowledge Sharing Motivation, Information \& Management, 2008, 45(1), pp. 65-74. Chen, R., Member Use of Social Networking Sites - An Empirical Examination, Decision Support Systems, 2013, 54(3), pp. 1219-1227. Jin, B., J.Y. Park, and H.-S. Kim, What Makes Online Community Members Commit? A Social Exchange Perspective, Behaviour \& Information Technology, 2010, 29(6), pp. 587-599.

Beldad, A., M. de Jong, and M. Steehouder, How Shall I Trust the Faceless and the Intangible? A Literature Review on the Antecedents of Online Trust, Computers in Human Behavior, 2010, 26(5), pp. 857-869.

Wasko, M.M. and S. Faraj, Why Should I Share? Examining Social Capital and Knowledge Contribution in Electronic Networks of Practice Management Information Systems Quarterly, 2005, 29(1), pp. 35-57. Organization Studies, 2007, 28(3), pp. 347-376. Communities, Information Systems Research, 2011, 22(4), pp. 841-854.

Ryssel, R., T. Ritter, and H.G. Georg, The Impact of Information Technology Deployment on Trust, Commitment and Value Creation in Business Relationships, Journal of Business \& Industrial Marketing, 2004, 19(3), pp. 197 - 207.

Perry, C., A. Cavaye, and L. Coote, Technical and Social Bonds Within Business-To-Business Relationships, Journal of Business \& Industrial Marketing, 2002, 17(1), pp. 75-88.

Jin, X.-L., M.K.O. Lee, and C.M.K. Cheung, Predicting Continuance in Online Communities: Model Development and Empirical Test, Behaviour \& Information Technology, 2009, 29(4), pp. 383-394.

Fang, Y.-H. and C.-M. Chiu, In Justice We Trust: Exploring Knowledge-Sharing Continuance Intentions in Virtual Communities of Practice, Computers in Human Behavior, 2010, 26(2), pp. 235-246.

Leimeister, J.M., W. Ebner, and H. Krcmar, Design, Implementation, and Evaluation Of Trust-Supporting Components in Virtual Communities for Patients, Journal of Management Information Systems, 2005, 21(4), pp. 101-131.

Gefen, D., E. Karahanna, and D.W. Straub, Trust and TAM in Online Shopping: An Integrated Model, Management Information Systems Quarterly, 2003, 27(1), pp. 51-90.

Chow, W.S. and L.S. Chan, Social Network, Social Trust and Shared Goals in Organizational Knowledge Sharing, Information \& Management, 2008, 45(7), pp. 458-465.

McKnight, D.H., V. Choudhury, and C. Kacmar, Developing and Validating Trust Measures for e-Commerce: An Integrative Typology, Information Systems Research, 2002, 13(3), pp. 334-359.

McKnight, D.H. and N.L. Chervany, What Trust Means in E-Commerce Customer Relationships: An Interdisciplinary Conceptual Typology, International Journal of Electronic Commerce, 2002, 6(2), pp. 35-59.

Benlian, A. and T. Hess, The Signaling Role of IT Features in Influencing Trust and Participation in Online Communities, International Journal of Electronic Commerce, 2011, 15(4), pp. 7-56.

Walczuch, R. and H. Lundgren, Psychological Antecedents of Institution-Based Consumer Trust in E-Retailing, Information \& Management, 2004, 42(1), pp. 159-177.

Awad, N. and A. Ragowsky, Establishing Trust in Electronic Commerce Through Online Word of Mouth: An Examination Across Genders, Journal of Management Information Systems, 2008, 24(4), pp. 101-121.

Jones, K. and L.N.K. Leonard, Trust in Consumer-To-Consumer Electronic Commerce, Information \& Management, 2008, 45(2), pp. 88-95.

Nolan, T., R. Brizland, and L. Macaulay, Individual Trust and Development of Online Business Communities, Information Technology \& People, 2007, 20(1), pp. 53-71.

Bhattacherjee, A., Individual Trust in Online Firms: Scale Development and Initial Test, Journal of Management Information Systems, 2002, 19(1), pp. 211-241.

Ridings, C.M., D. Gefen, and B. Arinze, Some Antecedents and Effects of Trust in Virtual Communities, Journal of Strategic Information Systems, 2002, 11(3-4), pp. 271-295.

8. Hu, P.J.-H., T.H.K. Clark, and W.W. Ma, Examining Technology Acceptance by School Teachers: A Longitudinal Study, Information \& Management, 2003, 41(2), pp. 227-241. 
DeLone, W., H. and E. McLean, R., The DeLone and McLean Model of Information Systems Success: A Ten-Year Update, Journal of Management Information Systems, 2003, 19(4), pp. 9-30.

80. Lin, H.-F. and G.-G. Lee, Determinants of Success for Online Communities: An Empirical Study, Behaviour \& Information Technology, 2006, 25(6), pp. 479-488.

81. Young, L. and S. Denize, A Concept of Commitment: Alternative Views of Relational Continuity in Business Service Relationships, Journal of Business \& Industrial Marketing, 1995, 10(5), pp. 2 - 37.

82. Chang, M.K., W. Cheung, and M. Tang, Building Trust Online: Interactions Among Trust Building Mechanisms, Information \& Management, 2013, 50(7), pp. 439-445.

83. Mason, C., T. Castleman, and C.M. Parker, Socio-Technical Factors Influencing Channel Use for Knowledge-Sharing in Regional SME Networks, International Journal of Knowledge Management Studies, 2008, 12(3), pp. 303 - 319.

84. Pavlou, P.A. and D. Gefen, Building Effective Online Marketplaces with Institution-Based Trust, Information Systems Research, 2004, 15(1), pp. 37-59.

85. Palvia, P., The Role of Trust in E-Commerce Relational Exchange: A Unified Model, Information \& Management, 2009, 46(4), pp. 213220 .

Morgan, R.M. and S.D. Hunt, The Commitment-Trust Theory of Relationship Marketing, Journal of Marketing Management, 1994, 58(3), pp. 20-38.

87. Kulkarni, U., S. Ravindran, and R. Freeze, A Knowledge Management Success Model: Theoretical Development and Empirical Validation, Journal of Management Information Systems, 2007, 23(3), pp. 309-347.

88. Rai, A., S.S. Lang, and R.B. Welker, Assessing the Validity of IS Success Models: An Empirical Test and Theoretical Analysis, Information Systems Research, 2002, 13(1), pp. 50-69.

89. Hew, K.F., Determinants of Success for Online Communities: An Analysis of Three Communities in Terms of Members' Perceived Professional Development, Behaviour \& Information Technology, 2009, 28(5), pp. 433-445.

90. Nelson, R.R. and P.A. Todd, Antecedents of Information and System Quality: An Empirical Examination Within the Context of Data Warehousing, Journal of Management Information Systems, 2005, 21(4), pp. 199-235.

91. Chakraborty, G., P. Srivastava, and D.L. Warren, Understanding Corporate B2B Web Sites' Effectiveness from North American and European Perspective, Industrial Marketing Management, 2005, 34(5), pp. 420-429.

Robbins, S.S. and A.C. Stylianou, Global Corporate Web Sites: An Empirical Investigation of Content and Design, Information \& Management, 2003, 40(3), pp. 205-212.

Lin, H., W. Fan, and P.Y.K. Chau, Determinants of Users' Continuance of Social Networking Sites: A Self-Regulation Perspective, Information \& Management, 2014, 51(5), pp. 595-603.

94. Wang, Y.-S., Assessing E-Commerce Systems Success: A Respecification And Validation of The Delone and Mclean Model of IS Success, Information Systems Journal, 2008, 18(5), pp. 529-557.

95. Yang, X., Y. Li, C.-H. Tan, and H.-H. Teo, Students' Participation Intention in an Online Discussion Forum: Why is ComputerMediated Interaction Attractive?, Information \& Management, 2007, 44(5), pp. 456-466.

96. Nicolaou, A.I. and D.H. McKnight, Perceived Information Quality in Data Exchanges: Effects on Risk, Trust, and Intention to Use, Information Systems Research, 2006, 17(4), pp. 332-351.

97. Ratnasingam, P., Trust in Inter-Organizational Exchanges: A Case Study in Business To Business Electronic Commerce, Decision Support Systems, 2005, 39(3), pp. 525-544.

98. Yang, Z. and X. Fang, Online Service Quality Dimensions and their Relationships With Satisfaction, International Journal of Service Industry Management, 2004, 15(3), pp. 302 - 326.

99. Yang, Z., S. Caib, Z. Zhouc, and N. Zhoua, Development and Validation of an Instrument to Measure User Perceived Service Quality of Information Presenting Web Portals, Information \& Management, 2005, 42(4), pp. 575-589.

100. Lee, G.-G. and H.-F. Lin, Customer Perceptions of E-Service Quality in Online Shopping, International Journal of Retail \& Distribution Management, 2005, 33(2), pp. 161 - 176.

101. Ho, C.-I. and Y.-L. Lee, The Development of an E-Travel Service Quality Scale, Tourism Management, 2007, $28(6)$, pp. 1434-1449.

102. Kuo, Y.-F., A Study on Service Quality of Virtual Community Websites, Total Quality Management \& Business Excellence, 2003, 14(4), pp. 461-473.

103. Elliot, S., G. Li, and C. Choi, Understanding Service Quality in a Virtual Travel Community Environment, Journal of Business Research, 2013, 66(8), pp. 1153-1160.

104. Lin, H.-F., Effects of Extrinsic And Intrinsic Motivation on Employee Knowledge Sharing Intentions, Journal of Information Science, 2007, 33(2), pp. 135-149.

105. Sun, H., Sellers' Trust and Continued Use of Online Marketplaces, Journal of the Association for Information Systems, 2010, 11(4), pp. $182-211$.

106. Sun, H., A Longitudinal Study of Herd Behavior in the Adoption and Continued Use of Technology, Management Information Systems Quarterly, 2013, 37(4), pp. 1013-1042.

107. Hsiu-Fen, L., Determinants of Successful Virtual Communities: Contributions from System Characteristics and Social Factors, Information \& Management, 2008, 45(8), pp. 522-527.

108. Tabachnick, B.G. and L.S. Fidell, Using Multivariate Statistics (4th Edition), 2007, Boston: Pearson.

109. Hair, J.F., W.C. Black, B.J. Babin, and R.E. Anderson, Multivariate Data Analysis, 7th ed, 2010, New Jersey: Pearson Prentice Hall.

110. Gerow, J.E., V. Grover, N. Roberts, and J.B. Thatcher, The Diffusion of Second-Generation Statistical Techniques in Information Systems Research from 1990-2008, Journal of Information Technology Theory and Application, 2010, 11(4), pp. 5-28. 
112. Field, A., Discovering Statistics using SPSS for Windows., ed. 2nd, 2000, London: Sage Publications.

113. Pallant, J., SPSS Survival Manual, 2005: Open University Press.

114. Podsakoff, P.M., S.B. MacKenzie, J.-Y. Lee, and N.P. Podsakoff, Common Method Biases in Behavioral Research: A Critical Review of the Literature and Recommended Remedies, Journal of Applied Psychology, 2003, 88(5), pp. 879-903.

115. Ahuja, M.K., K.M. Chudoba, C.J. Kacmar, D.H. McKnight, and J.F. George, It Road Warriors: Balancing Work-Family Conflict, Job Autonomy, and Work Overload to Mitigate Turnover Intentions, Management Information Systems Quarterly, 2007, 31(1), pp. 1-17.

116. Liang, H., N. Saraf, Q. Hu, and Y. Xue, Assimilation of Enterprise Systems: The Effect Of Institutional Pressures and the Mediating Role of Top Management, Management Information Systems Quarterly, 2007, 31(1), pp. 59-87.

117. Faul, F., E. Erdfelder, A. Buchner, and A.-G. Lang, Statistical power analyses using G*Power 3.1: Tests for correlation and regression analyses, Behavior Research Methods, 2009, 41(4), pp. 1149-1160.

118. Hanus, B. and Y.A. Wu, Impact of Users' Security Awareness on Desktop Security Behavior: A Protection Motivation Theory Perspective, Information Systems Management, 2016, 33(1), pp. 2-16.

119. Preacher, K.J. and A.F. Hayes, Asymptotic and Resampling Strategies for Assessing and Comparing Indirect Effects in Multiple Mediator Models, Behavior Research Methods, 2008, 40(3), pp. 879-891.

120. Chang, H.H. and S.W. Chen, Consumer Perception of Interface Quality, Security, and Loyalty in Electronic Commerce, Information \& Management, 2009, 46(7), pp. 411-417.

121. Dabholkar, P.A. and R.P. Bagozzi, An Attitudinal Model of Technology-Based Self-Service: Moderating Effects of Consumer Traits and Situational Factors, Journal of the Academy of Marketing Science, 2002, 30(3), pp. 184-201.

122. Shang, R.-A., Y.-C. Chen, and H.-J. Liao, The Value of Participation in Virtual Consumer Communities on Brand Loyalty, Internet Research, 2006, 16(4), pp. 398 - 418.

123. Dabholkar, P.A., W.M.v. Dolen, and K.d. Ruyter, A Dual-Sequence Framework for B2C Relationship Formation: Moderating Effects of Employee Communication Style in Online Group Chat, Psychology \& Marketing, 2009, 26(2), pp. 145-174.

124. Chen, I.Y.L., The Factors Influencing Members' Continuance Intentions in Professional Virtual Communities: A Longitudinal Study, Journal of Information Science, 2007, 33(4), pp. 451-467.

125. Xu, B. and D. Li, An Empirical Study of the Motivations for Content Contribution and Community Participation in Wikipedia, Information \& Management, 2015, 52(3), pp. 275-286.

126. Hsiao, C.-C. and J.-S. Chiou, The Impact of Online Community Position On Online Game Continuance Intention: Do Game Knowledge and Community Size Matter?, Information \& Management, 2012, 49(6), pp. 292-300.

127. Amani, Z., Commitment as a Mediator of the Relationship between Trust and Relationship Loyalty to Retailer, Journal of Business Studies Quarterly, 2015, 6(3), pp. 144-163.

128. Everard, A. and D.F. Galletta, How Presentation Flaws Affect Perceived Site Quality, Trust, and Intention to Purchase from an Online Store, Journal of Management Information Systems, 2005, 22(3), pp. 56 - 95.

129. Cohen, J. and P. Cohen, Applied Multiple Regression/Correlation Analysis for the Behavioral Sciences, 1993, Hillsdale, NJ: Lawrence Erlbaum.

130. Aiken, L.S. and S.G. West, Multiple Regression: Testing and Interpreting Interactions, 1991, Thousand Oaks, CA: Sage. 